Journal of Al-Azhar University Engineering Sector

Vol.15, No. 56, July, 2020, 886-903

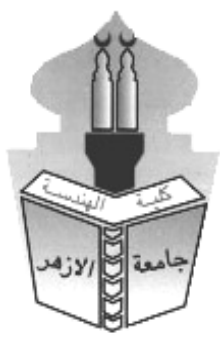

\title{
AN ANALYTICAL STUDY OF THE CONCEPTS AND VALUES OF ISLAMIC ARCHITECTURE WITH CIVILIZATION CONTINUITY FOR UMM AL-QURA UNIVERSITY - MAKKAH AL-MUKARRAMAH KINGDOM OF SAUDI ARABIA
}

\author{
Aly Elmansoury \\ Architectural Department, College of Engineering, Al-Azhar University, Cairo, Egypt \\ E-mail: Ail.elmansory@azhar.edu.eg
}

\begin{abstract}
With the advancement of technical development in the methods of architecture and the intertwining of different cultures into our Arab and Islamic societies, the architect became confused regarding utilizing contemporary techniques, besides, preserving the positives of buildings in their Islamic nature and represented in the use of Islamic values and concepts, so the current paper aimed to clarify those positives and motives that contributed In the formation of its brilliant architectural elements, which had a role in creating an Islamic personality and architectural character. The present paper shed light on the most important design criteria and foundations that were built on Islamic values and concepts, which were then used in many local and international projects, and in order to deal with the importance of the paper and the goals that must be achieved, the application of this paper on one the universities of the Kingdom of Saudi Arabia, a university Umm Al-Qura in Makkah Al-Mukarramah, with architectural significance, in five points: (Islamic content - environmental concept - concept of aesthetic formation).

The importance of the study lies in its discussion of a highly sensitive topic that serves contemporary Islamic architecture, where the importance of influencing the values and concepts of Islamic architecture and its clear and directed role in the design, in order to provide an urban environment for the user that serves his aspirations and deals with all the surrounding conditions and develops belonging to him. The research aims to analyze and study the most important concepts and values of Islamic architecture and the associated design criteria and principles that help direct the design process towards an urban product of functional, formative, and historical religious value, in order to infer the extent of its application and how this is taken into account in our future design considerations. In the context of the questions raised by the importance of the study and its goals that we seek to achieve, it is clear that the study should adopt an inductive analytical approach, and analyze one of the architecturally recent examples that are closely related to Islamic architecture due to the impact of its educational role and the dissemination of the thought affected by its urban environment, namely Umm Al Qura University in its location, design and future goals.
\end{abstract}

KEYWORDS: Environmental Concept, Spatial Concept, Organic Concept, Aesthetic Formation Concept. and Contemporary Islamic Architecture. 


\section{دراسة تحليلية لمفاهيم وقيم العمارة الإسلامية ذات الاستمرارية الحضارية لجامعة أم القرىـ مكة المكرمة

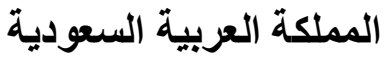 \\ على عبد الله المنصوري

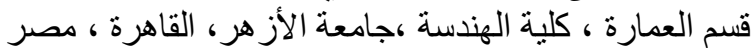

E-mail: Ail.elmansory@azhar.edu.eg البريد الاليكترونية الأنمارة

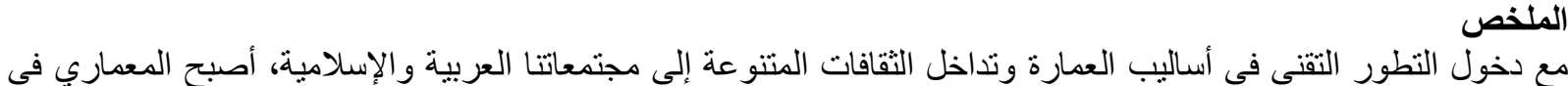

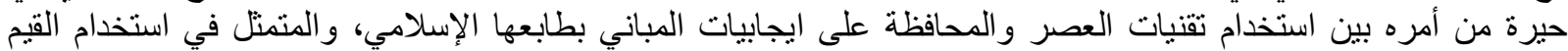

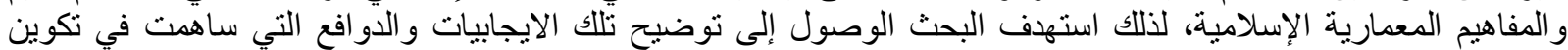
عناصر ها المعمارية الر ائعة و التي كان لها دور في إيجاد شخصية وطابع معماري إلىلامي مميز.

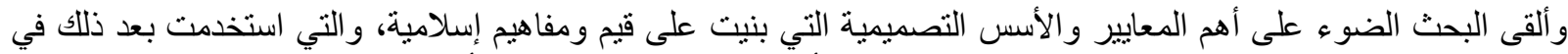

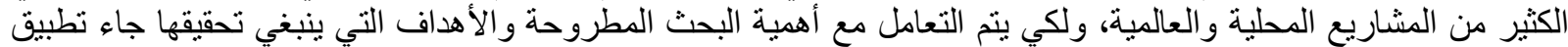

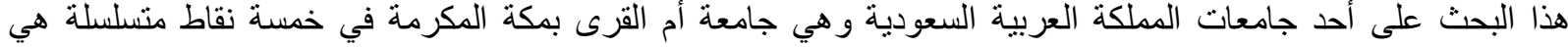

(المضمون الإسلامي - المفهوم البيئي - مفهوم التشكيل الجمالي).

وتكمن أهمية الدراسة في تطرقها إلى موضو ع ذو حساسية عالية يخدم العمارة الإسلامية المعاصرة، حيث الأهمية الواضحة

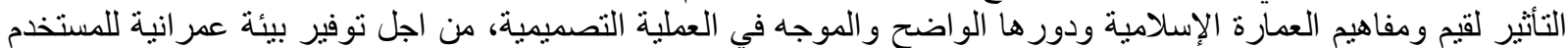

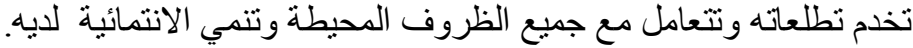

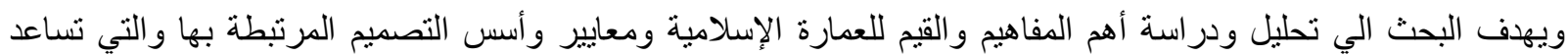

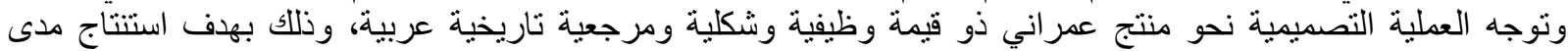

تطيقها وكيفية اخذ ذلك في اعتبار اتتا التصميمية المستقبلية.

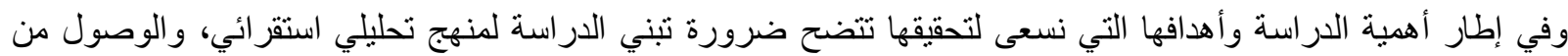

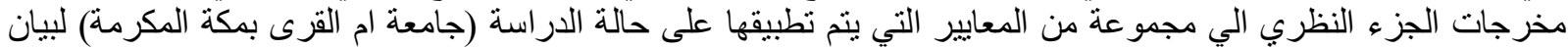
مدى تو افقها مع معايير وقيم العمارة الإسلامية.

الكلمات المفتاحية : المفهوم البيئي ،المفهوم الفراغي ، المفهوم التشكيل العضوي ، مفهوم التثكيل الجمالي، و العمارة

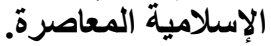

1/مفاهيم وقيم العمارة العربية الإسلامية:

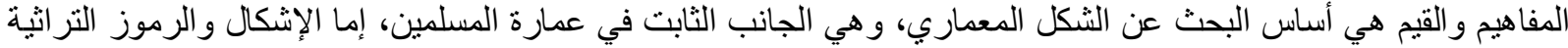

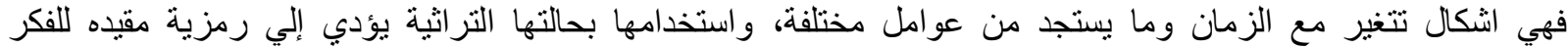

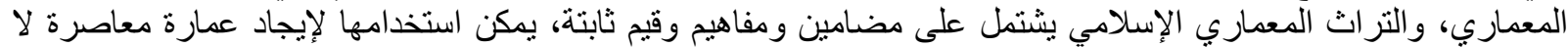

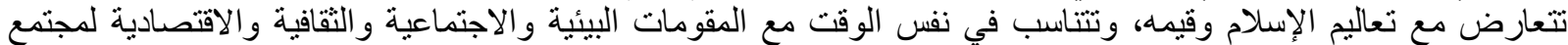

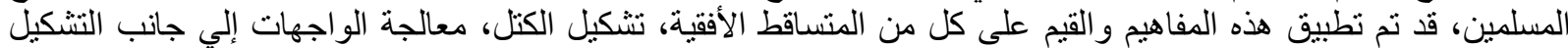

جدول رقم ( ) مفاهيم وقيم العمارة الإسلامية ذات الاستمرارية الحضاري

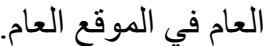

مفاهيم وقيم العمارة الإسلامية ذات الاستمرارية الحضارية

\begin{tabular}{|c|c|c|}
\hline المفهوم الجمالي & المفهوم البيئي & صمون الإسلاهي \\
\hline 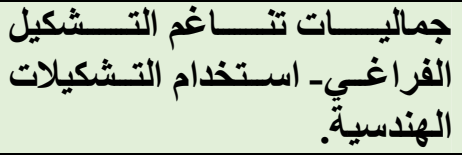 & 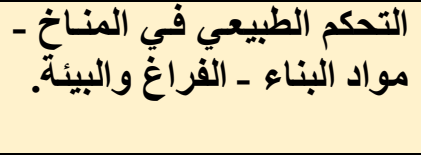 & 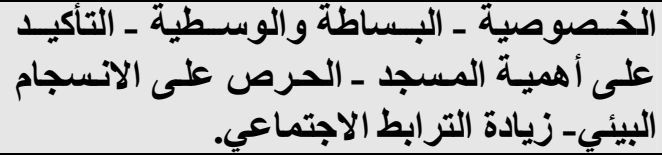 \\
\hline
\end{tabular}




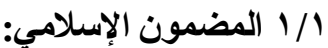

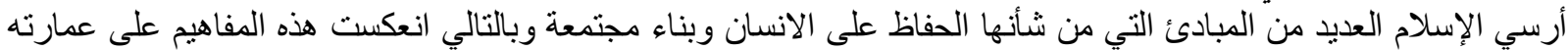

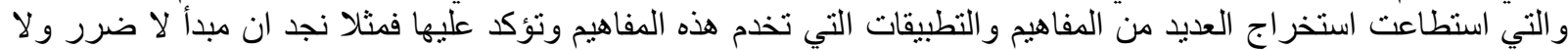

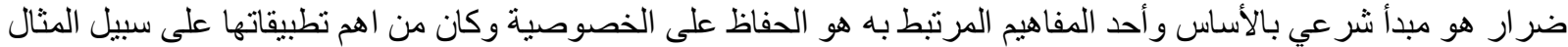

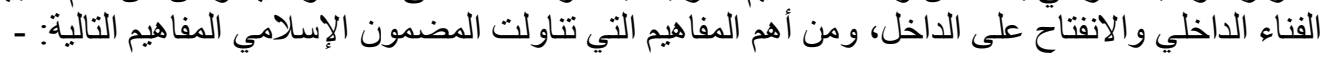

• مراعاة الخصوصية: تعتبر الخصوصية من أهم القيم ومفاهيم المضمون الإسلامي ومن أهم العوامل الأساسية

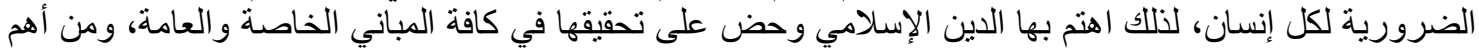

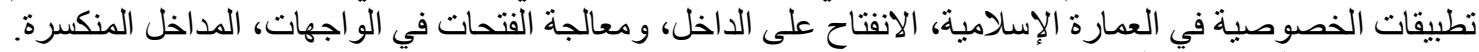

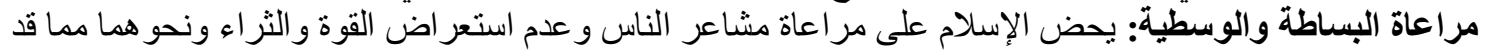

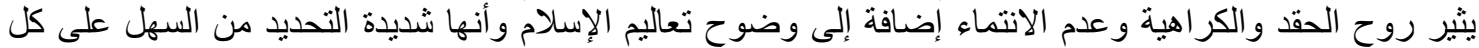

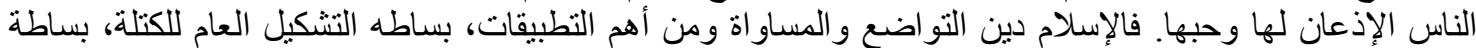

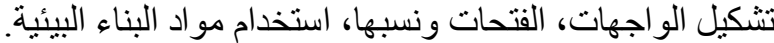

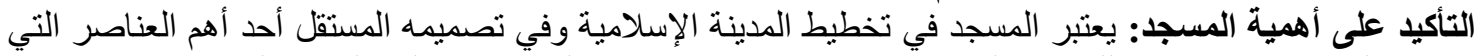

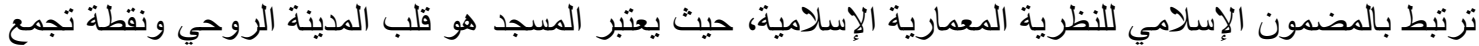

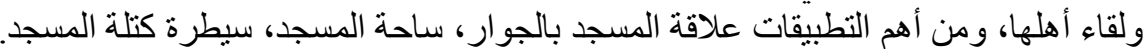

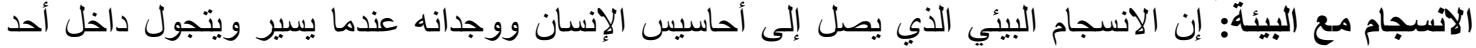

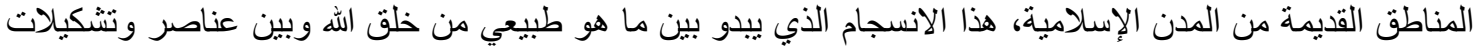

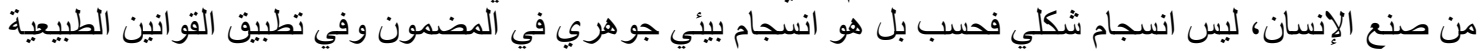
و التي تتضح في الطابع المعماري للو اجهات، التدرج الفراغي ودرجات الحرارة، عناصر التنسيق البيئي، استخدام المواد الطبيعية. الترابط الاجتماعي: يعتبر الترابط و التكافل الاجتماعي من القيم السامية للدين الإسلامي الحنيف والتي النعكست

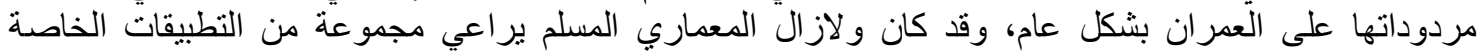

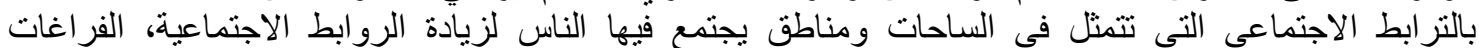
و الممرات الي جانب توفير بعض الآنُشئة التي تمارس في الفر اغات العامة.

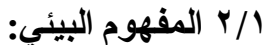

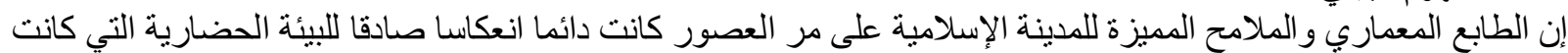

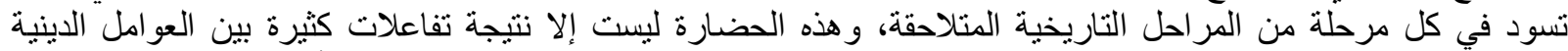

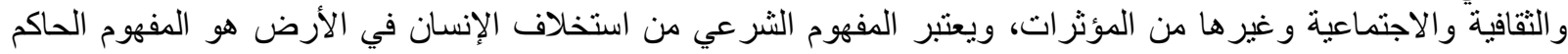

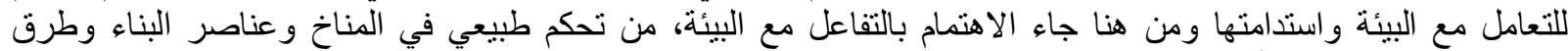

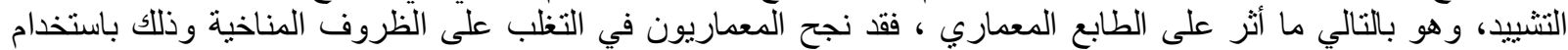

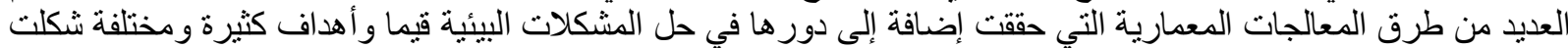
أسس ومعايير للتصميم المعماري من خلال المفهوم البيئي وتحقيقا للففهوم الثنر في التي.

التحكم الطبيعي في المناخ :يعتبر التحكم في المناخ بطرقه المعمارية المختلفة أحد المجالات التي أبدع فيها المعماري

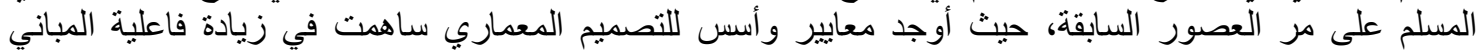

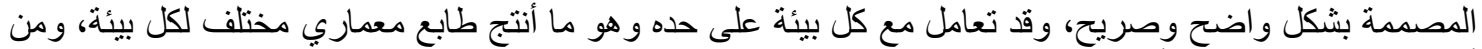

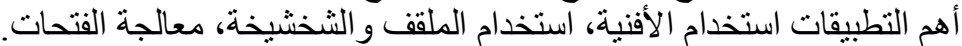

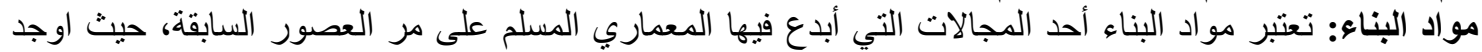

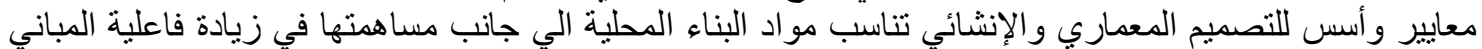

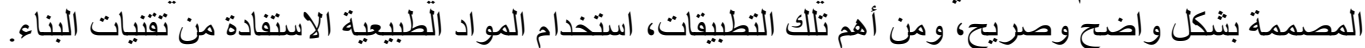

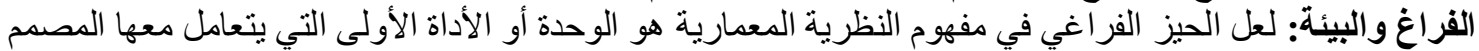

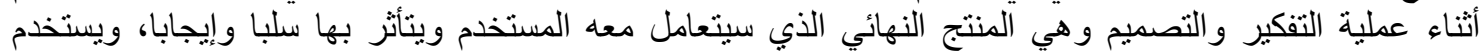

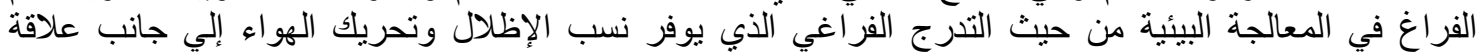
الفر اغات الداخلية بالخارجية المظللة والغير مظللة، حجم الفراغ اغن وتأثيره على التهوية داخلة. 


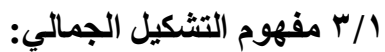

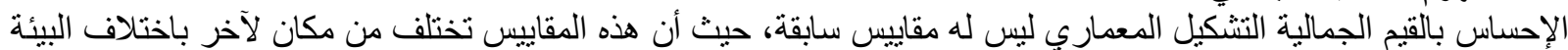

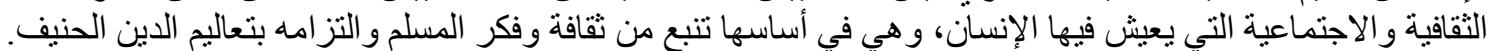

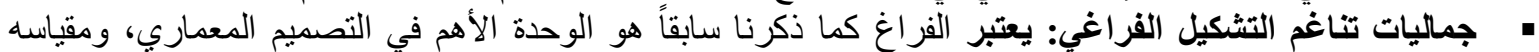

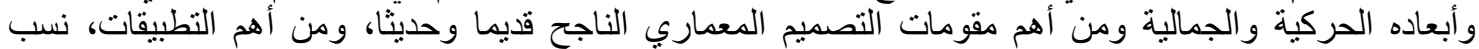

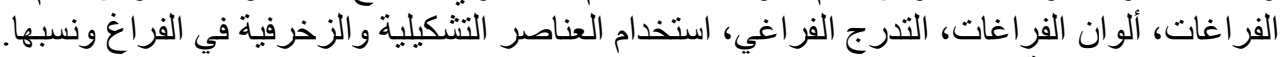

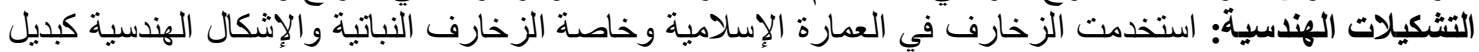

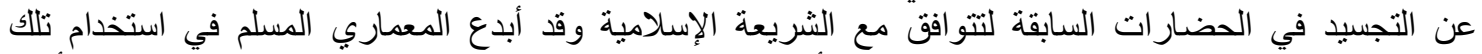

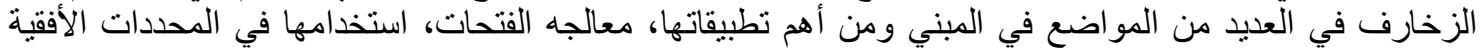

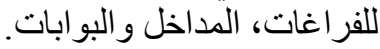

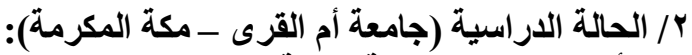

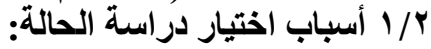

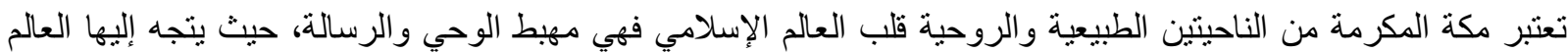

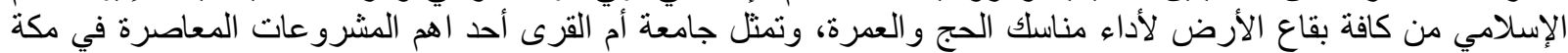

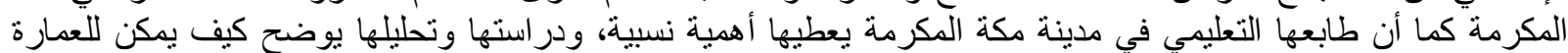

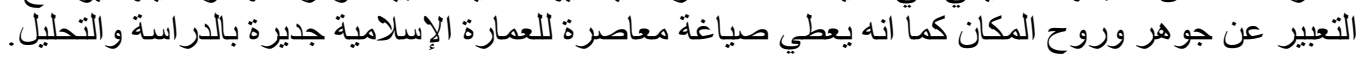

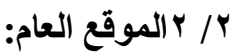

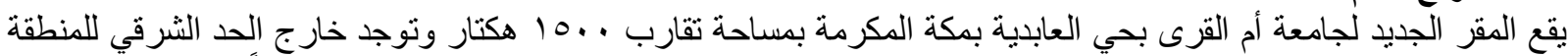
الحضرية لمكة المكرمة مباشرة وجنوب سهل عرفات، ويبعد الموقع عن المسجد الحرام حوالي ع ال كم شرقاً.

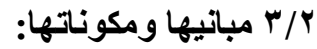

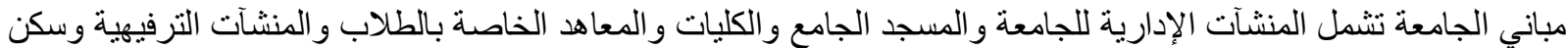

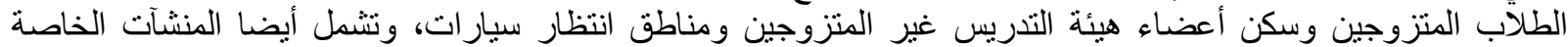

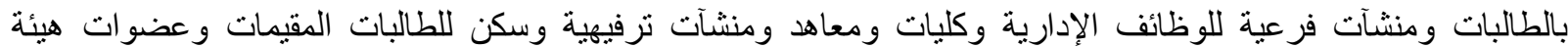

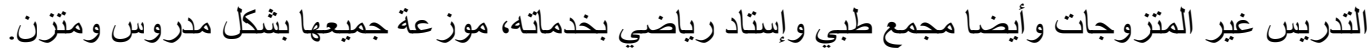

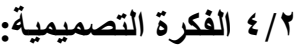

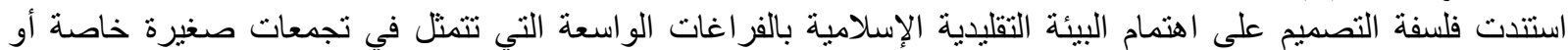

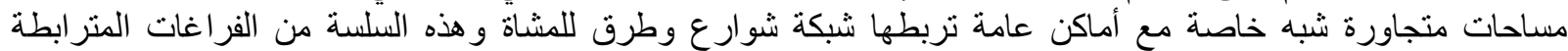

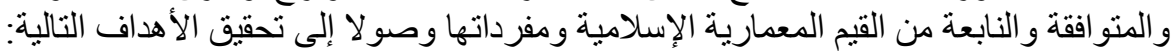

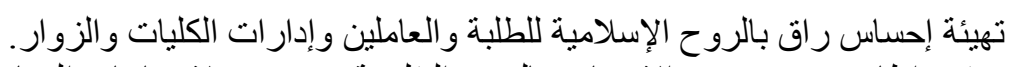

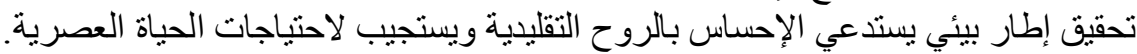

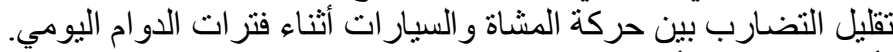

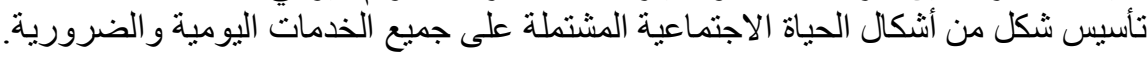

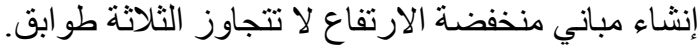

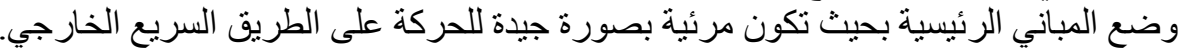
استخدام التقنيات العصرية الحيثة بما يتو افق مع التقاليد و القيم و المفاهيم الإسلامية الرئر اسخة.

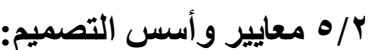

اعتمدت الفكرة التصميمية للمنطقة الأكاديمية لقسم الطلاب بالحرم الجامعي الجديد على الأسس التالية:

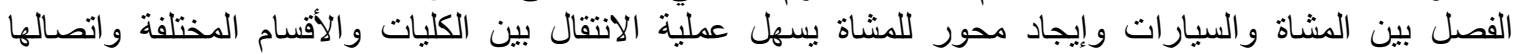

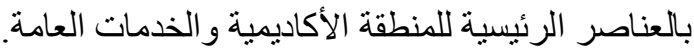

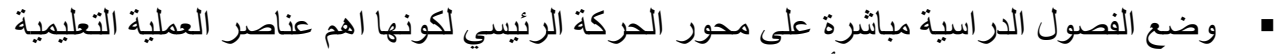

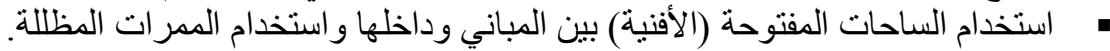




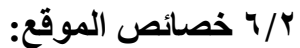

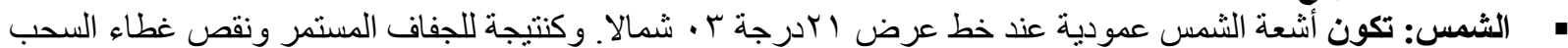

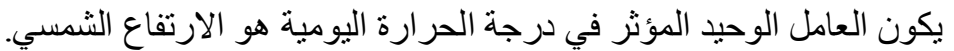

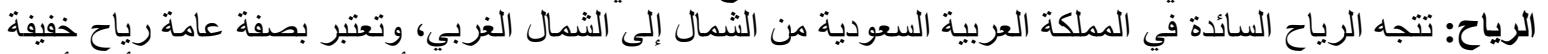

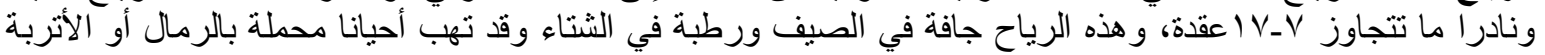

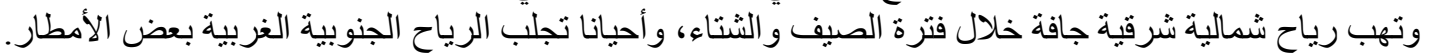

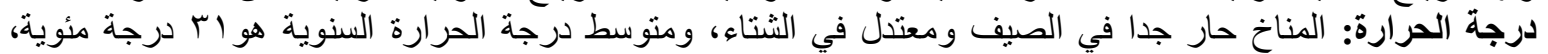

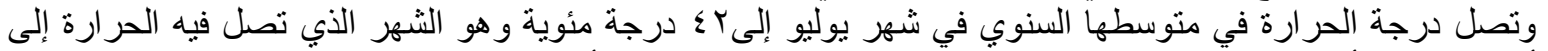

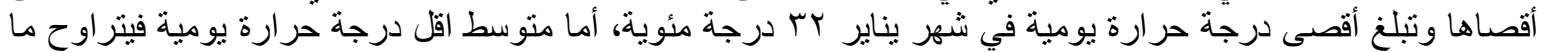

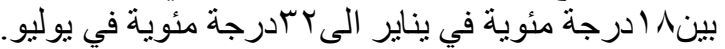

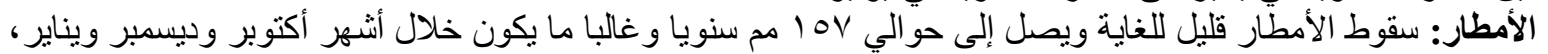

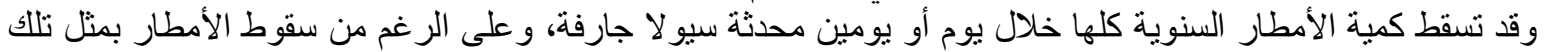
الكثافة لا يعتبر من الأمور المألوفة، ألا أن بعضا من تلأك السيول سبيت تلفا جسيما بالموقع خلال الكئل السنوات العشرين
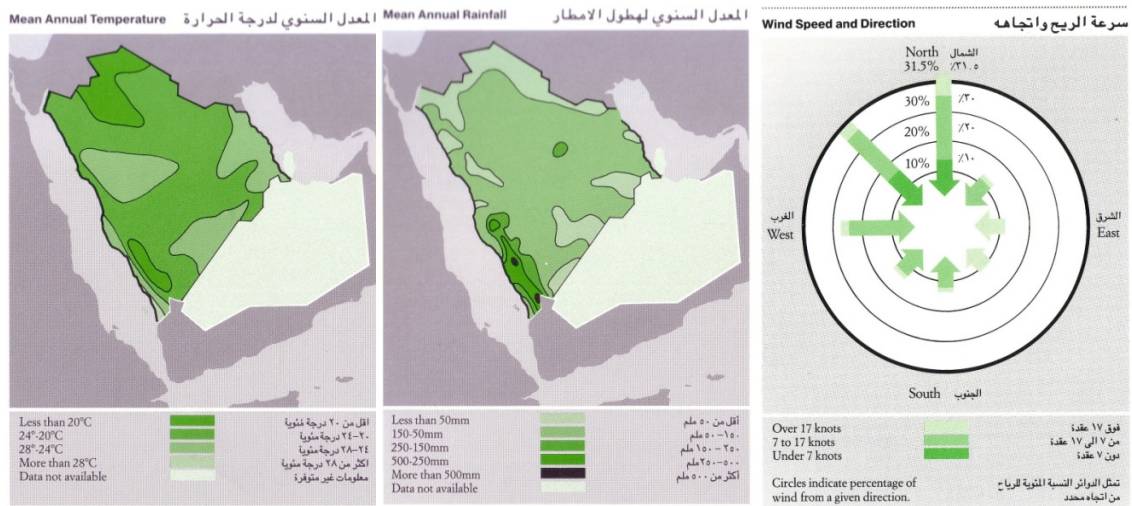
نفاذ اشعة الشمس

شكل ( ) يوضح (تحليل أثتعة الثمس وتأثير ها - وحركة الرياح واتجاهتها - تحليل معدل هطول الامطار -تحليل درجات الحرارة).

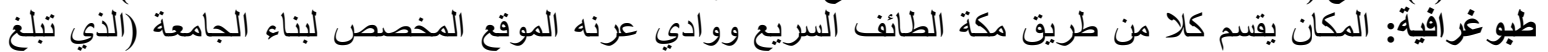

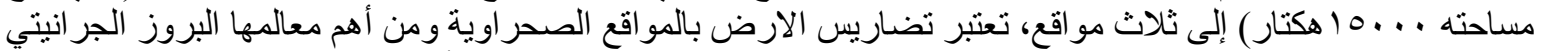

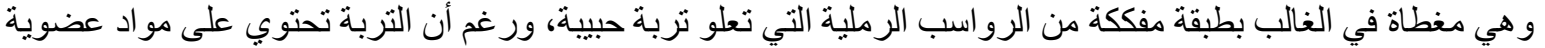

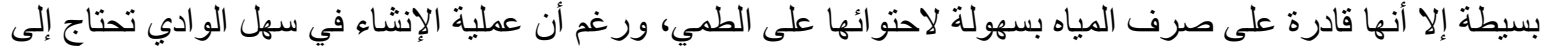

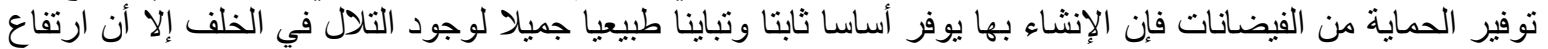

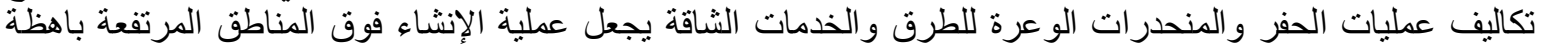
التكاليف. الوديان : يتأثر الموقع إلى حد كبير بالتقاء أثثين من الوديان الرئيسية هما وادي عرنه ووادي النعمان و هما الواديان اللذان

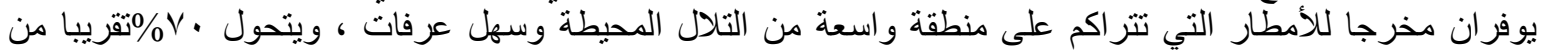

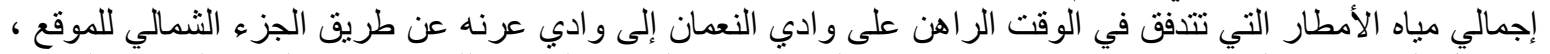

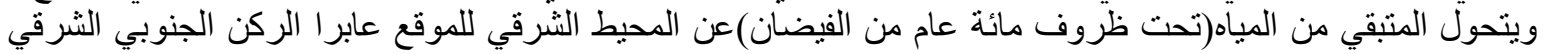

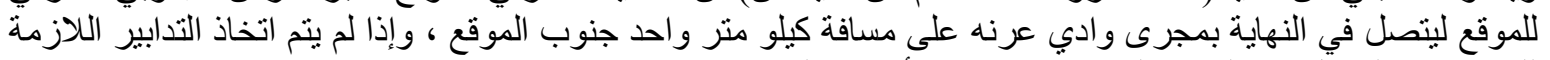

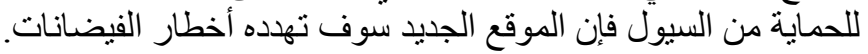

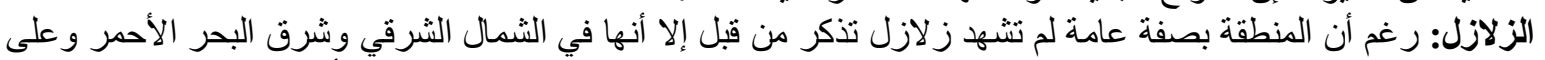

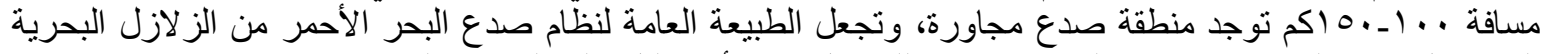

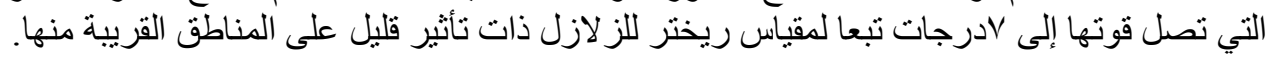




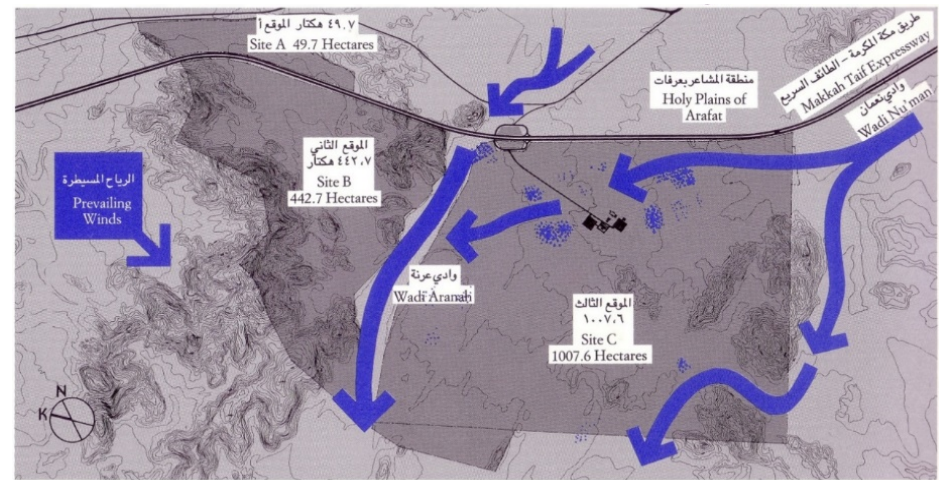

شكل (r) يوضح خصائص الموقع الطبيعية.

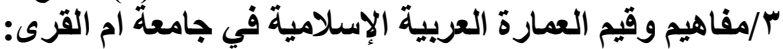

يتناول هذا الجزء تطبيق مفاهيم العمارة الإسلامية التي تقدمت على دراسة الحالة لبيان مدي توافقها مع مفاهيم وقيم العمارة

الإسلامية.

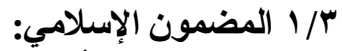

يردف المشروع بالأساس الي إيجاد بيئة تعليمية متوافقة مع المضمون الإسلامي ومتوافقة مع العصر ليقدم نموذج لعمارة

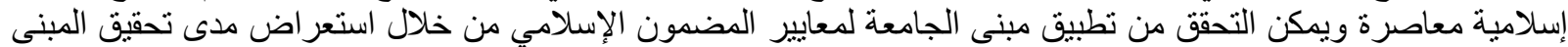

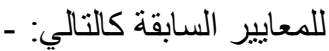

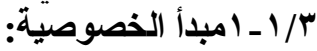

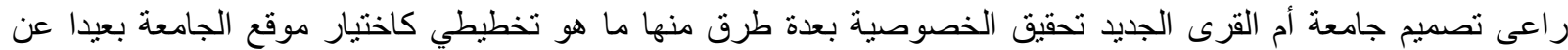

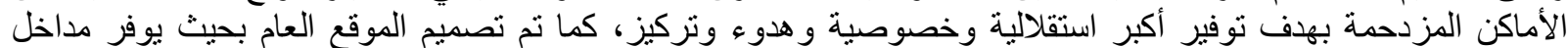
وبو ابات تساعد على إعطاء الإحساس باستقلالية وخصوصية الموقع العام وسهولة الرقابة الأمنية يتناول مبدأ الخصوصية الخية النقاط التالية:

ا ـ الانقتاح على الداخل: تحقق الانفتاح على الداخل في مبنى الجامعة من خلال استخدام افنية بداخل مباني الكليات لإنارة

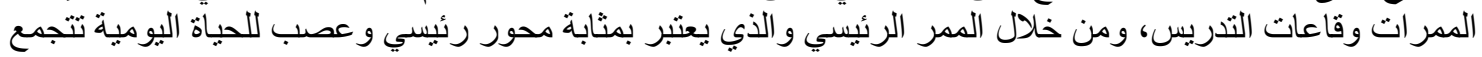
حوله الكليات. r ـ معالجة الواجهات: استخدام التشكيلات الهندسية لمعالجة الواجهات لتوفير الظلال ولتحقيق طابع معماري مميز يتو افق مع الطابع التقليدي ولكن بصورة التهات معاصرة.

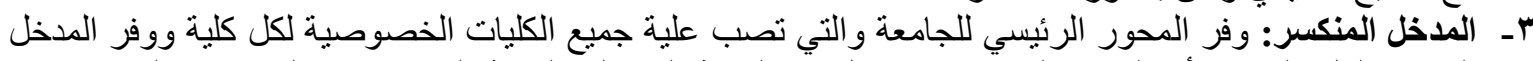

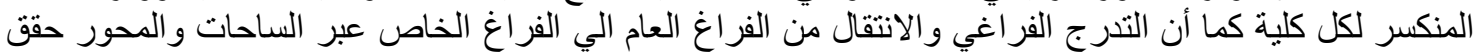
فكرة المداخل المنكسرة وأعطى الخصوصية التهل لكل كلية على حدة.

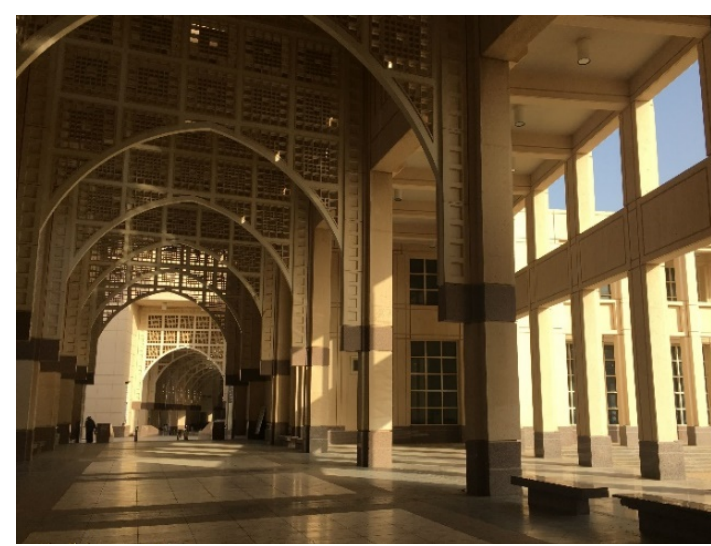

شكل (ّ) يوضح الاهتمام بالطابع المعماري الإسلامي و المحلي بشكل خاص.

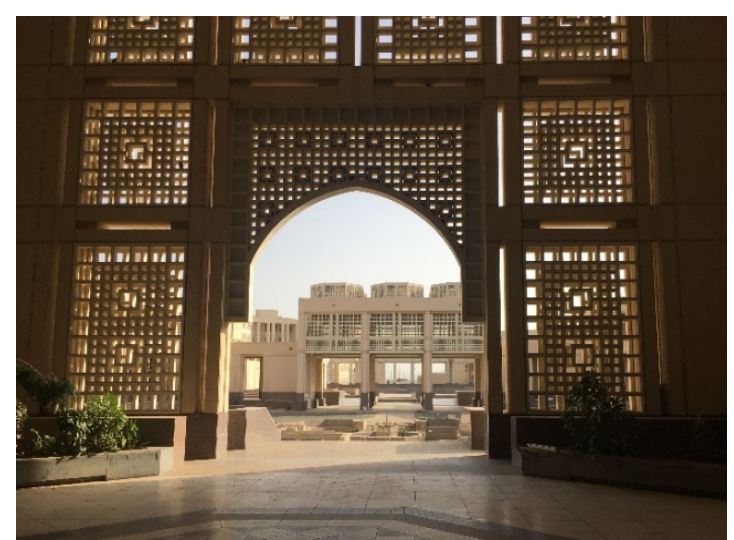



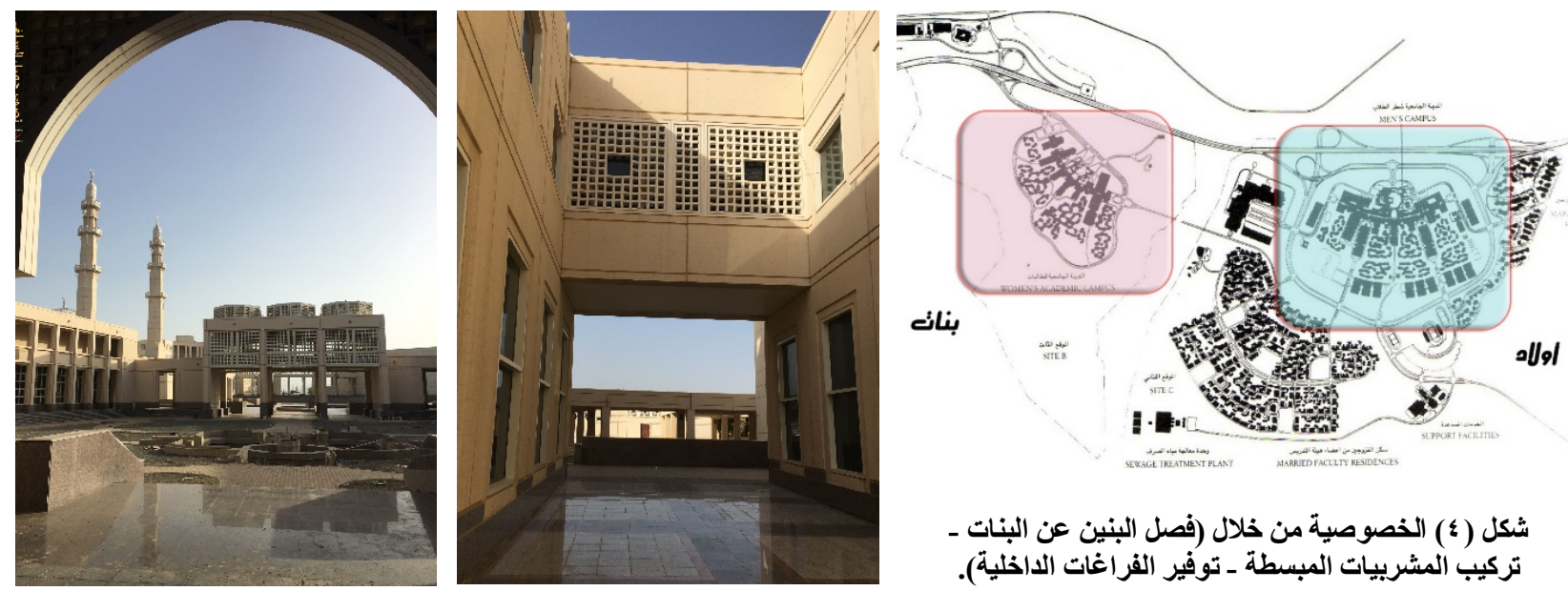

شكل ( ؛ ) الخصوصية من خلال (فصل البنين عن البنات -

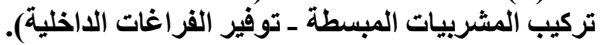

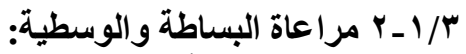

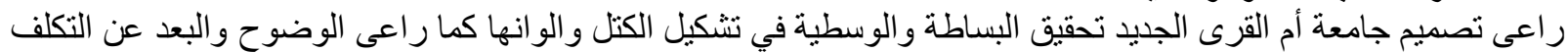

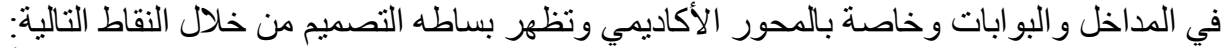

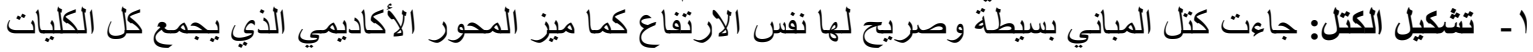

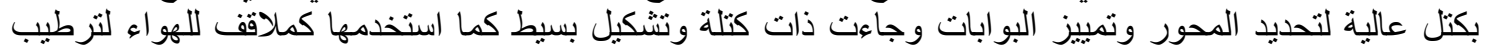

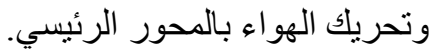
r- تثكيل الواجهات: تم توحيد الواجهات وتثكيلها من خلال وحدة مديولية بسيطة استخدمت في معالجه الفتحات

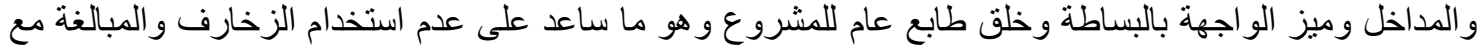

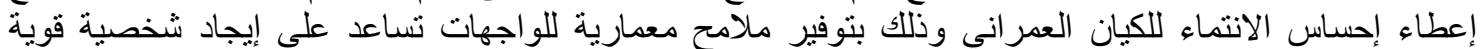

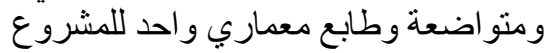

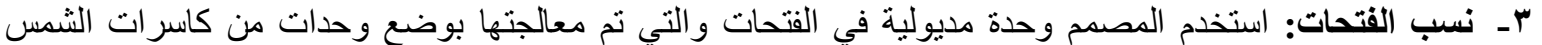

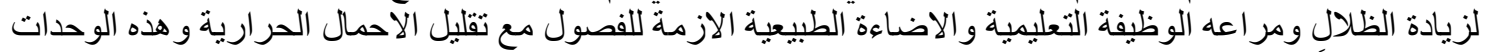

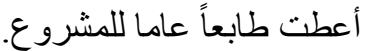

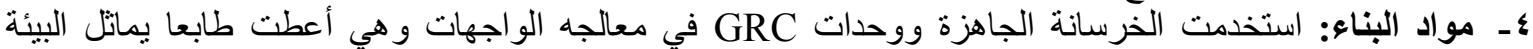

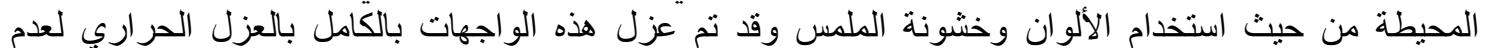
مناسبتها للبيئة بدون عزل الو اجهات.

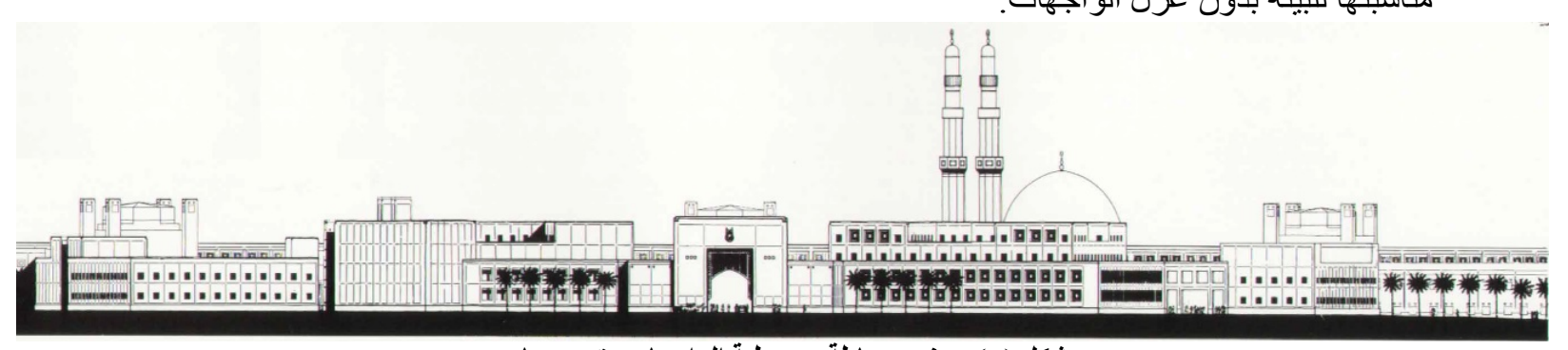

شكل (0) يوضح بساطة ووسطية الواجهات وتوحيد ها. 


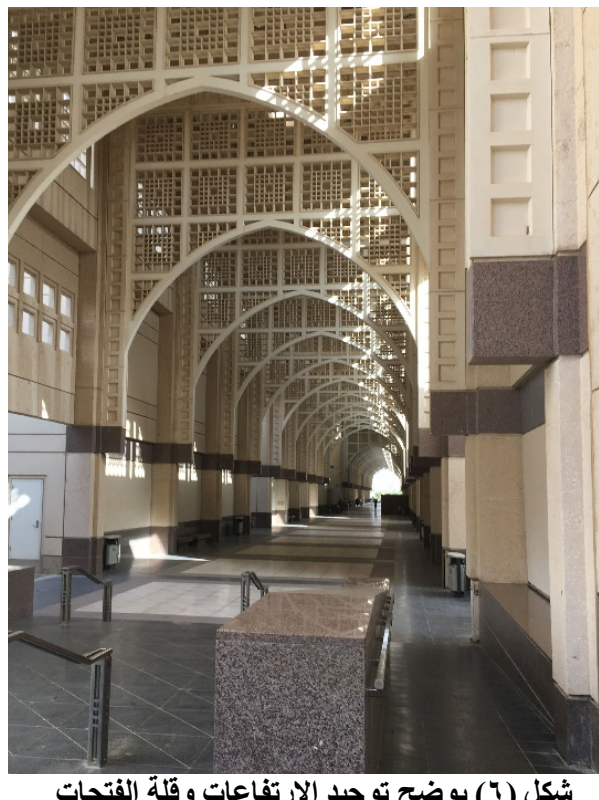

شكل (ך) يوضح توحيد الارتفاعات وقلة الفتحات.

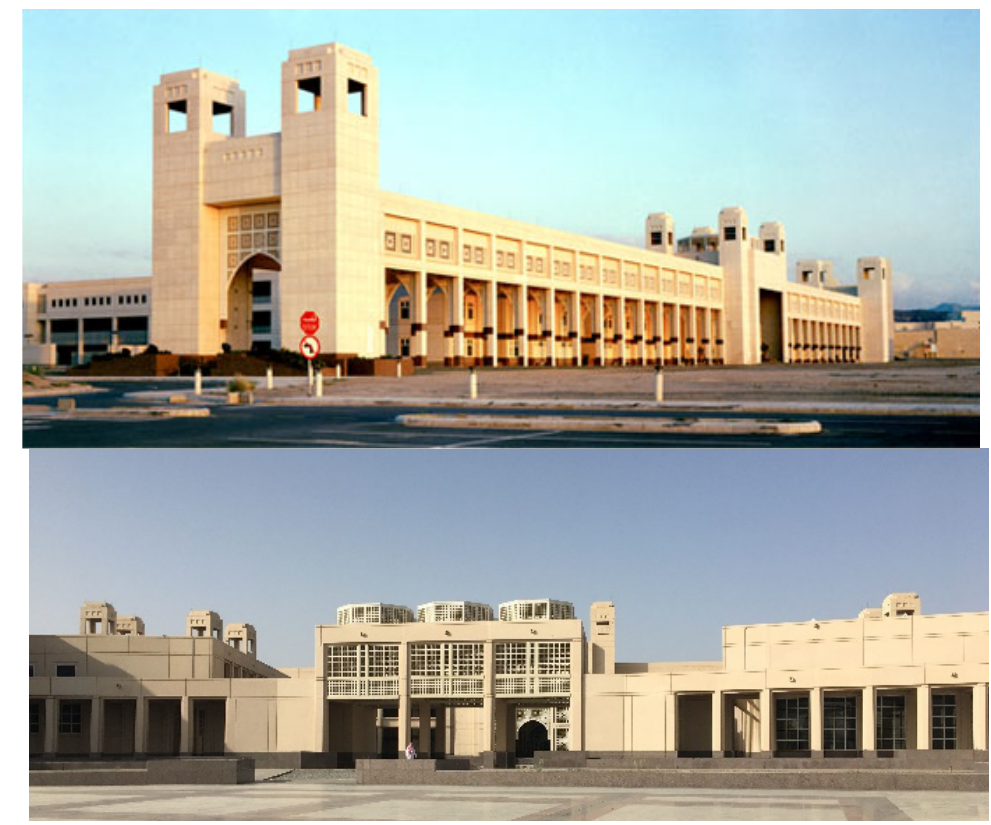

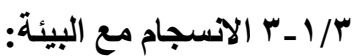

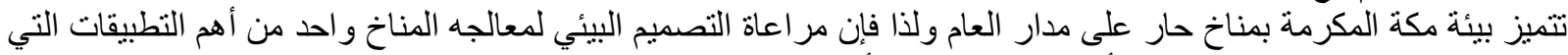

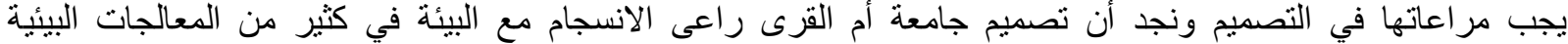

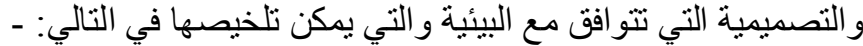

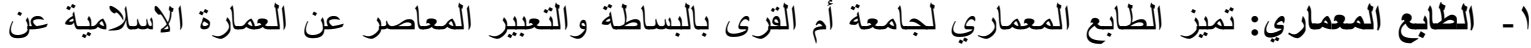

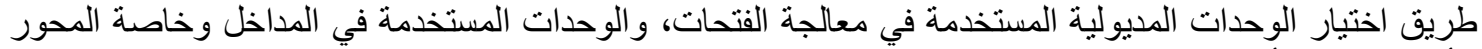

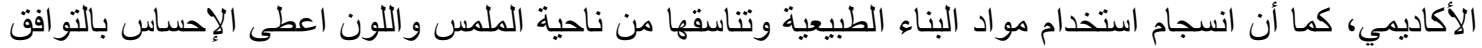
مع البيئة. r- التذرج الفراغي ودرجات الحرارة: راعى التصميم التدرج الفراغي من الفراغات المفتوحة الي الفراغات شبة

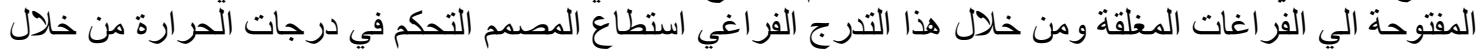

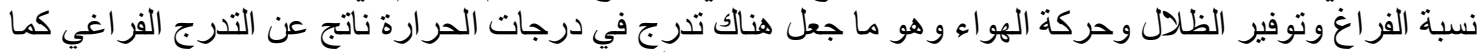

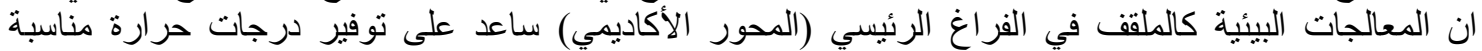

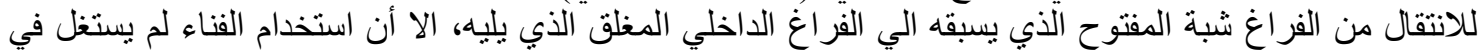

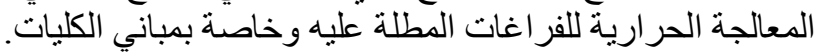

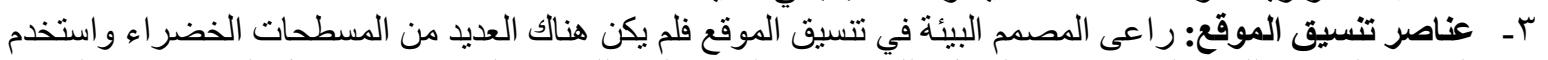

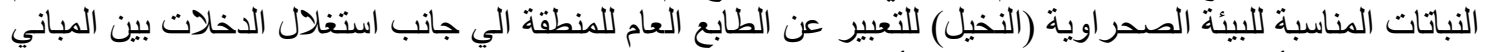

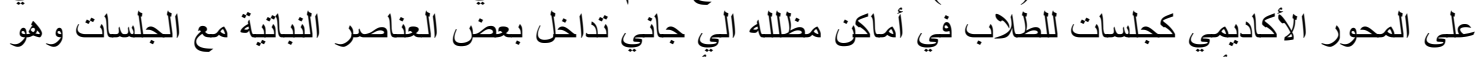

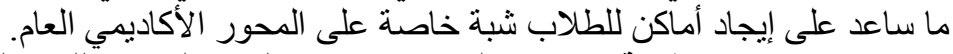

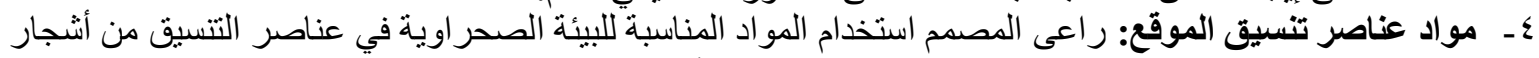

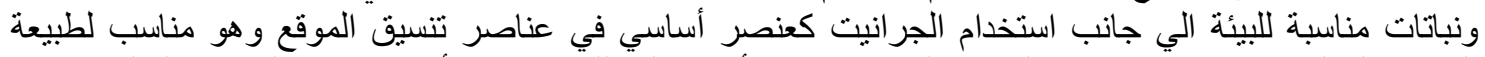

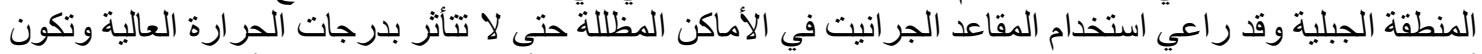

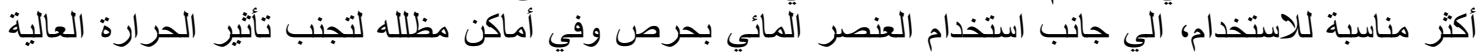

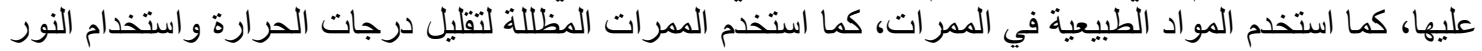
و الظل كعنصر من عناصر تنسيق الموقع. 

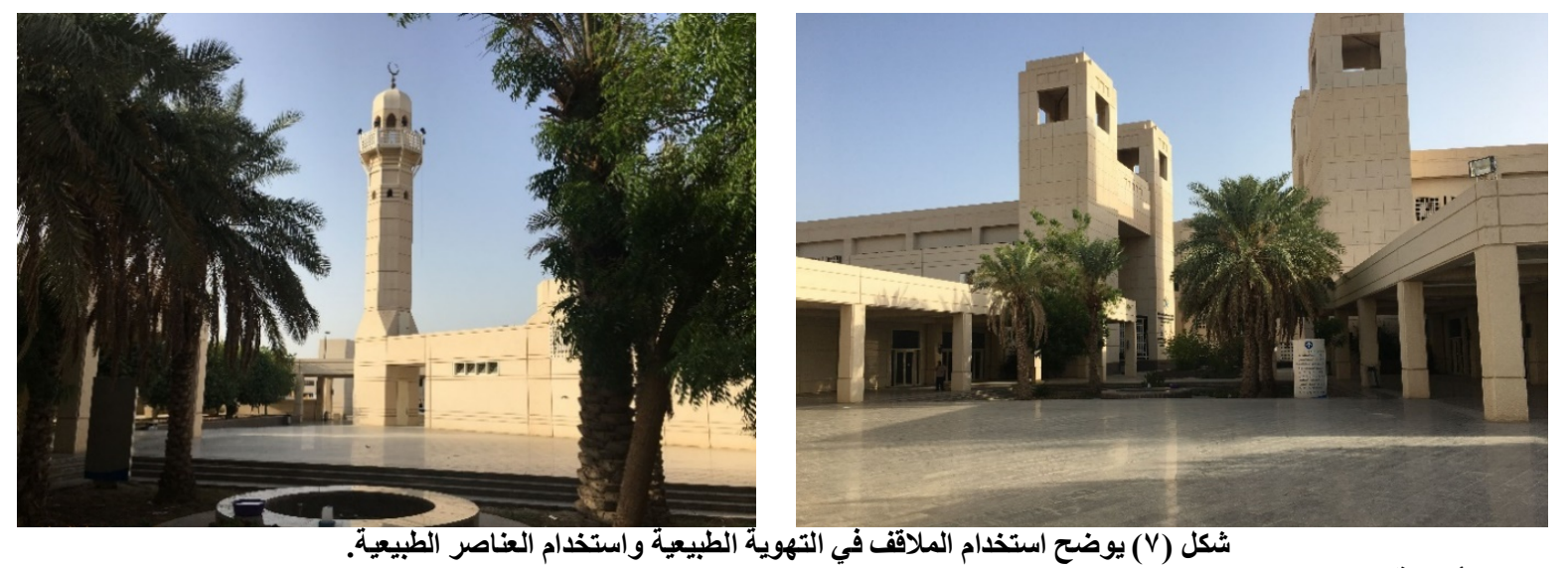

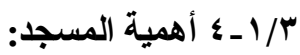

لكتلة المسجد نأثير كبير على التثكيل العام للجامعة ويرجع ذلك الى تأثثير المآذن العالية على التشكيل الر اسي الي جانب القبة

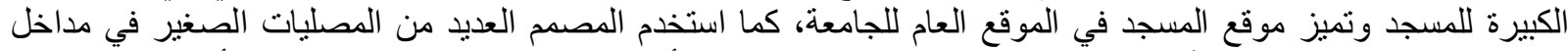

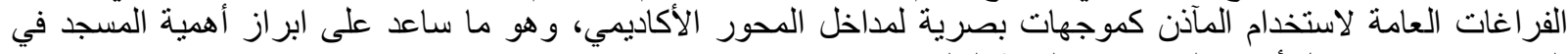

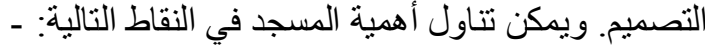

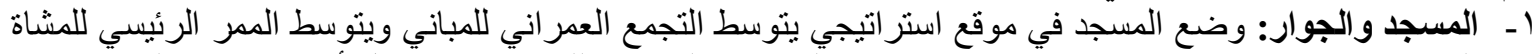

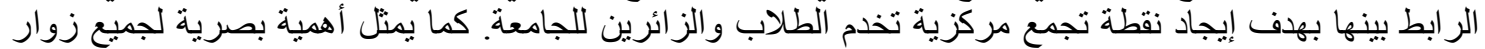

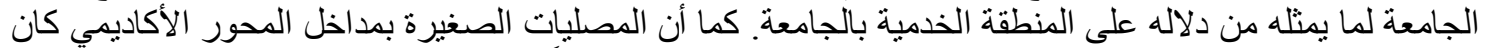

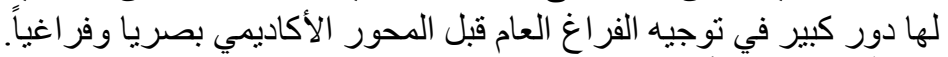

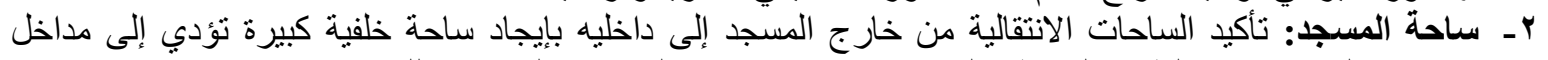

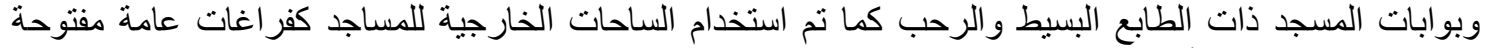

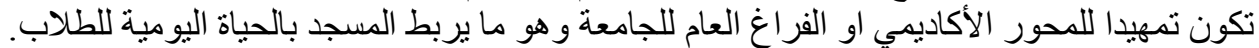

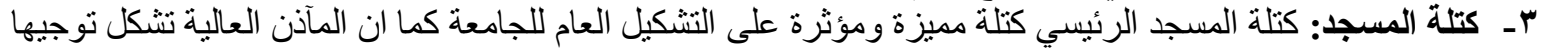

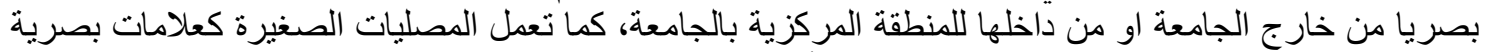
وفر اغية للفر اغات العامة التي تمثل مداخل للمحور الأكاديمي.
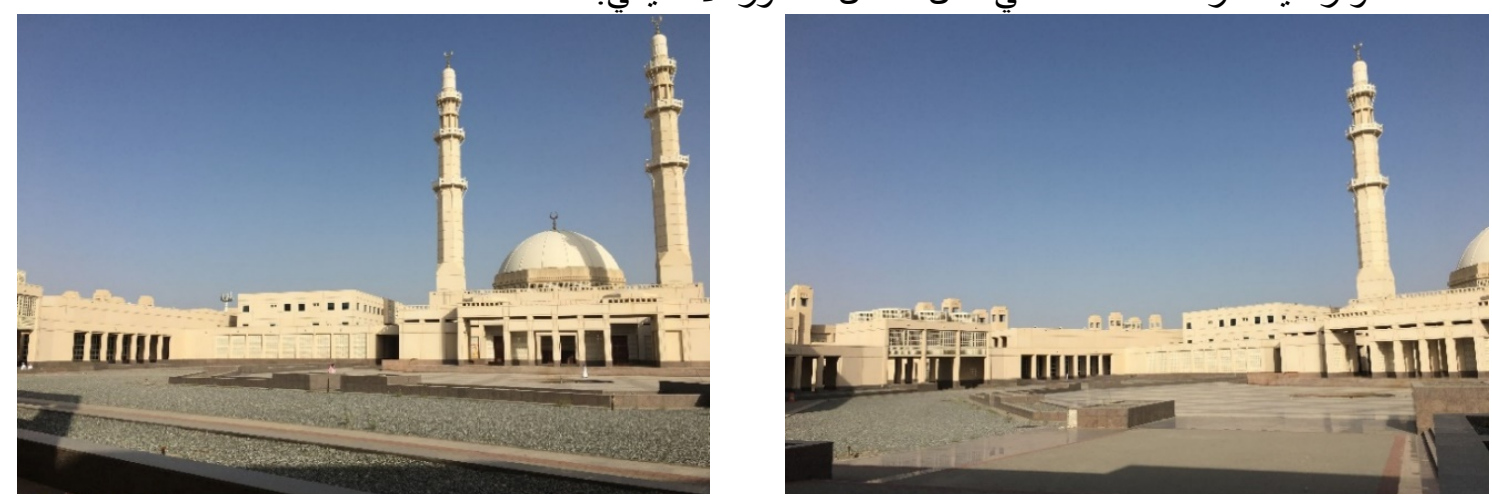

شكل (^) يوضح مسجد الجامعة الرئيسي.

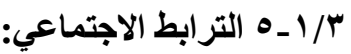

راعى تصميم الجامعة البعد الاجتماعي من خلال ممارسة الأنشطة العامة و التي تزيد التر ابط بين الطلاب ليس فقط على مستوى الكلية الواحدة ولكن لجميع طلاب الجامعة و ذللك من خلال التالي: -

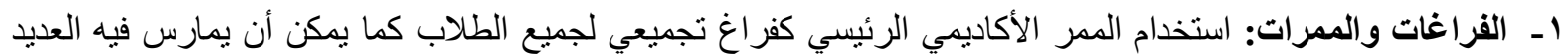

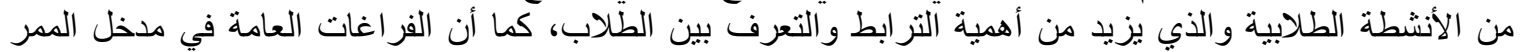

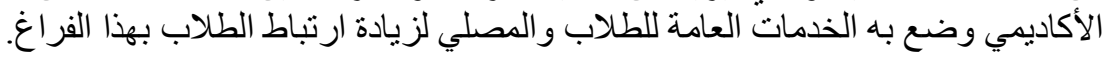


r- ـ أنثطة الفراغ العام: تتنوع أنشطة الفراغ العام من أنشطة خدمية وتعليمية وترفيهية وهو ما يساعد على ترابط الطلاب التباب و عدم الاقتصار على الأنشطة الأكاديمية فقط في الفراغ التعلئيمي و هو ما يربط الطلاب بالفر اغ أغ العام وجعله أكثر تفاعلا.
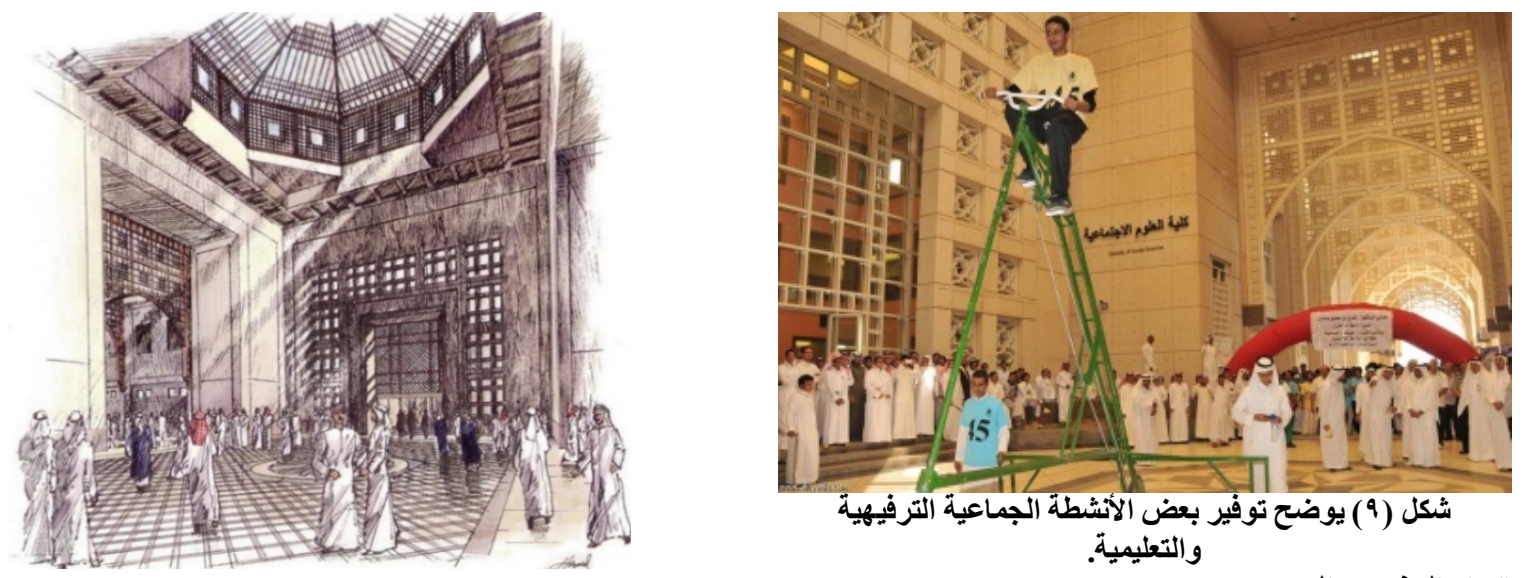

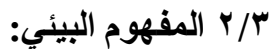

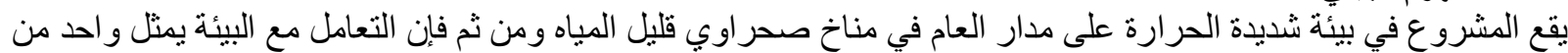

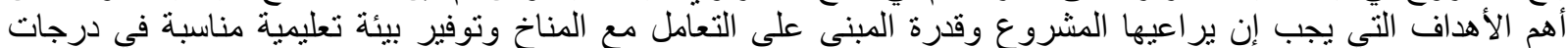

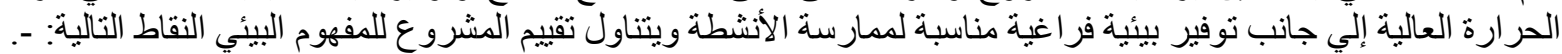

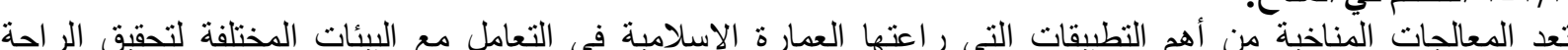

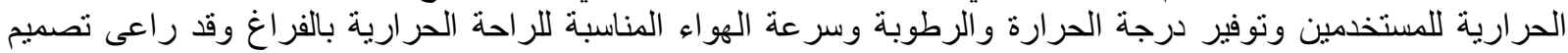

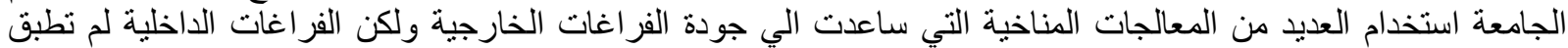
المعالجات المناخية على الرغم من وجودها وذللك نتيجة تكييف المبنى بالكامل ويتلخص التصاع التحكم في المناخ في النقاط التالية: -

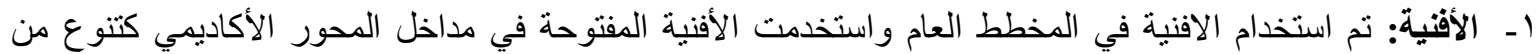

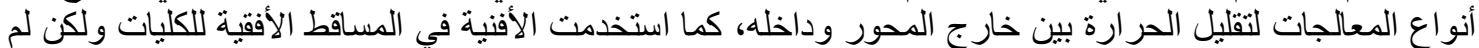

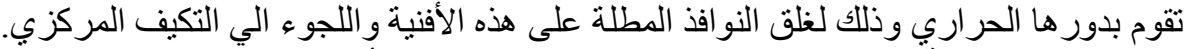

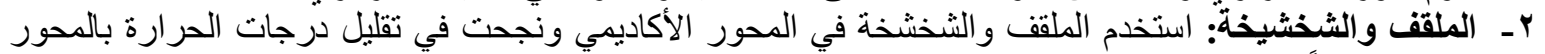

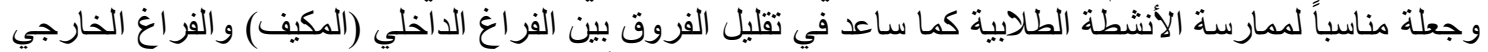

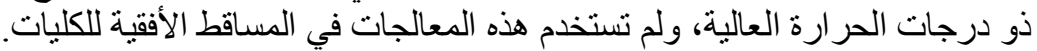

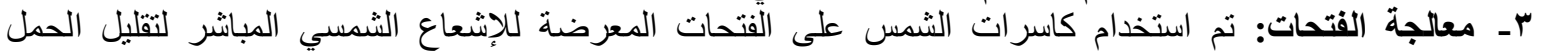

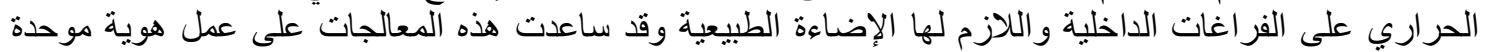

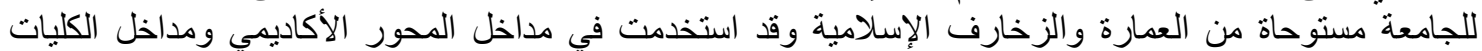
بمعالجات مختلفة مع ثوحيد الوحدة المديولية. 
در اسة تحليلية لمفاهيم وقيم العمارة الإسلامية ذات الاستمر ارية الحضارية لجامعة أم القرى- مكة المكرمة المملكة العربية السعودية

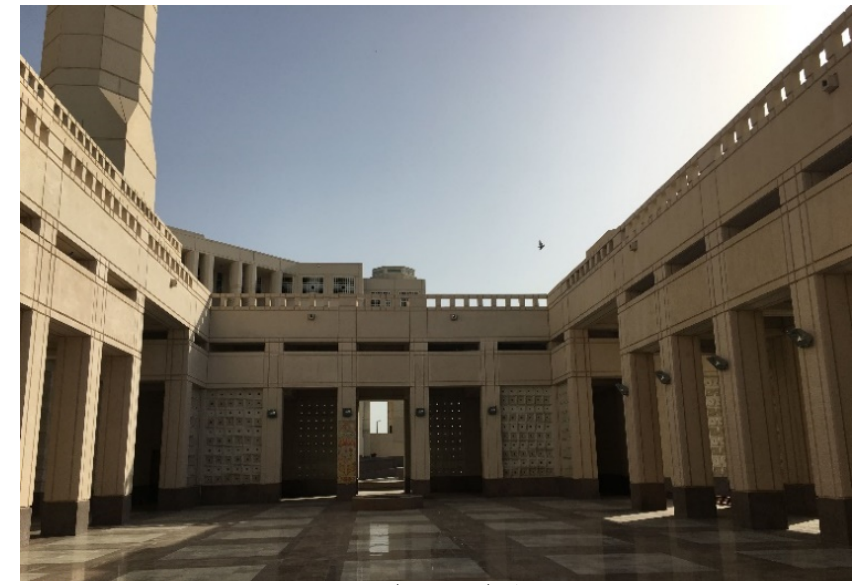

شكل ( • () يوضح استخذام الافنية الداخلية كمنظ حراري والتوجيه للاخل.
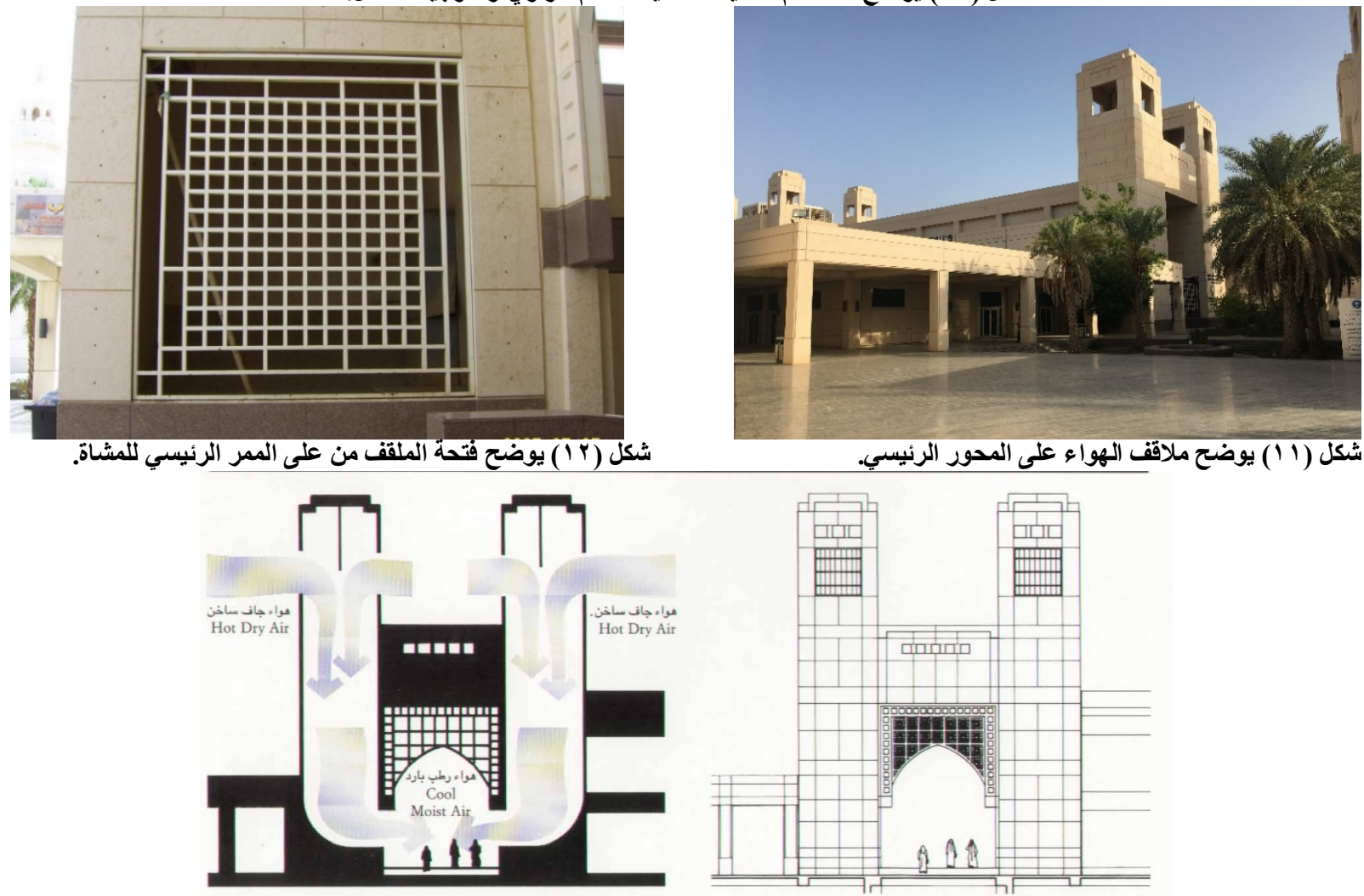

شكل (ب ا ) يوضح تحليل حركة الهواء في الملقف . 

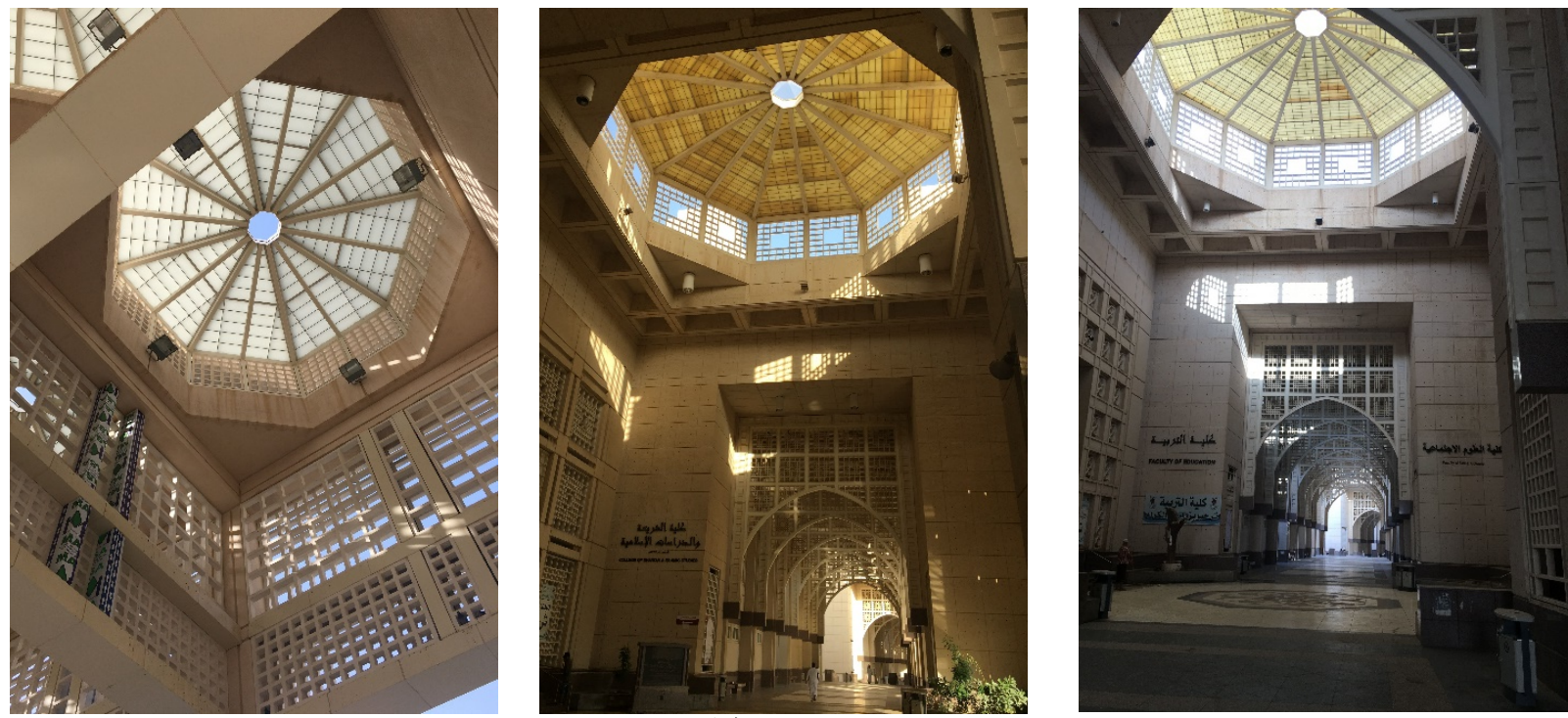

شكل (ع ا ) يوضح استخلام غصر الشخشيخة في سحب وتفريغ الهواء الساخن.
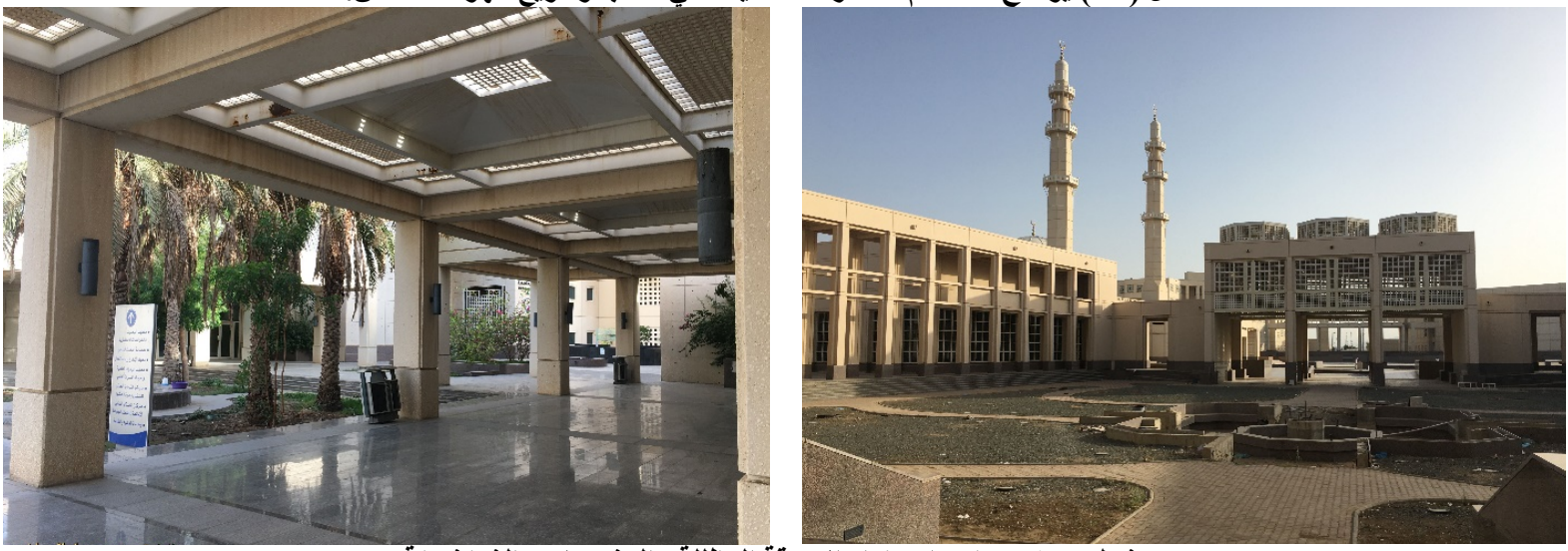

شكل (0 1 ) يوضح استخدام الاروقة المظللة والمشربيات والثخشيخة

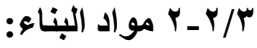

راعى التصميم استخدام أساليب البناء المتعددة مواد البناء مناسبة للموقع وسرعة التبناء التفيذ وقد استخدمها بما يتو افق مع البيئة

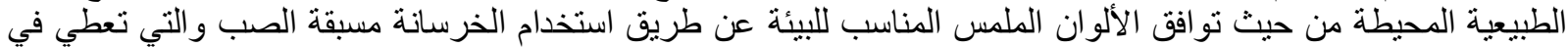

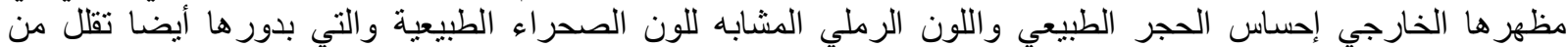
امتصاص أشعة الثمس بشكل كبير.

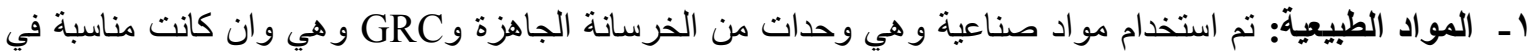

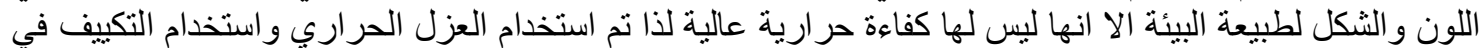

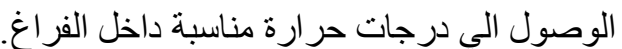

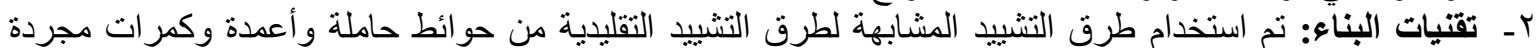

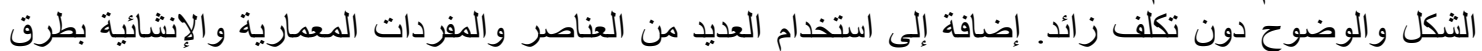

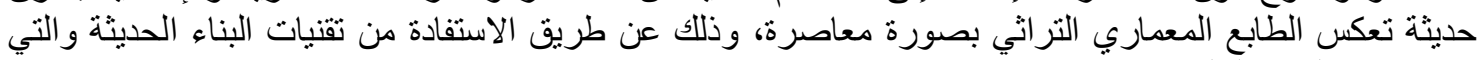

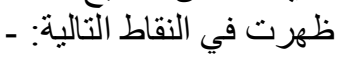

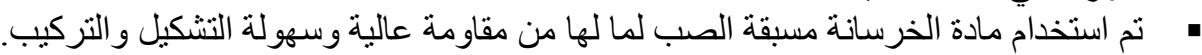

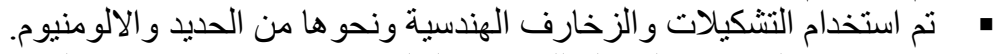

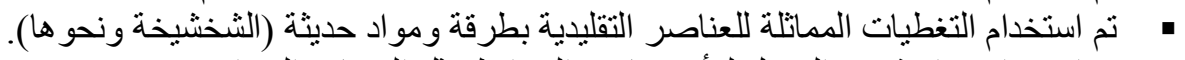
• تم استخدام مواد شديدة التحمل للأرضيات والحو ائط منل الرخام و الجر انيت. 

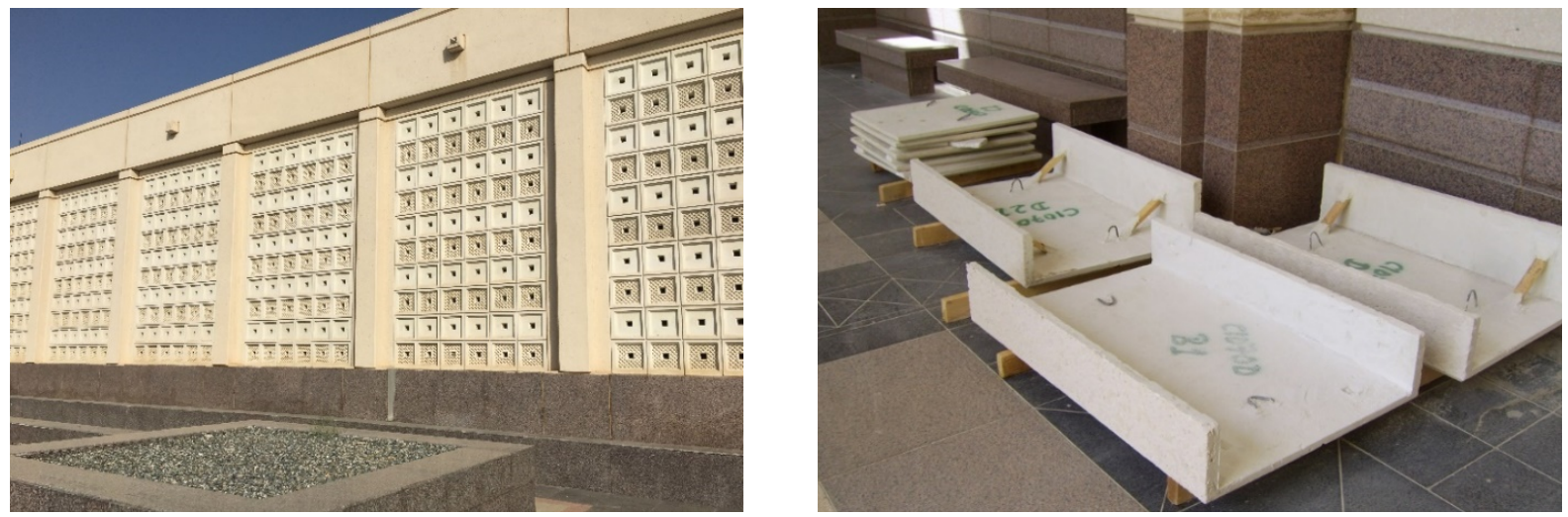

شكل (7 17 ) يوضح استخدام مواد تكسيه خرسانية مشابهة للطبيعية.

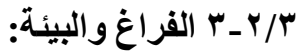

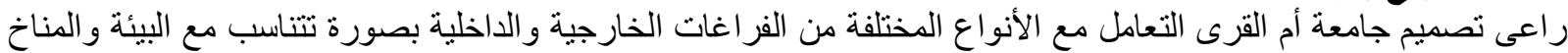

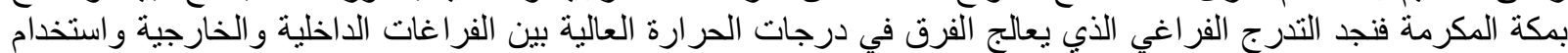

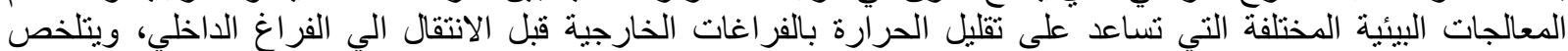
التعامل البيئي للفر اغات في النقاط التالية: -

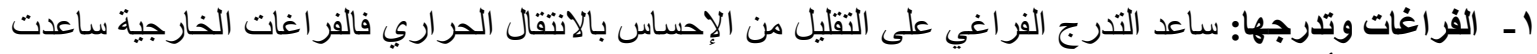

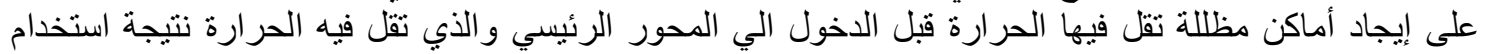

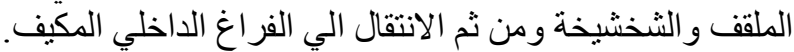

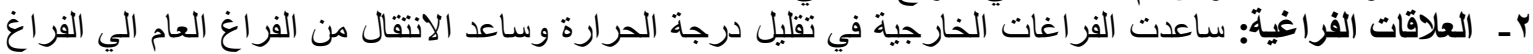

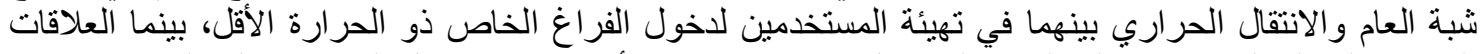

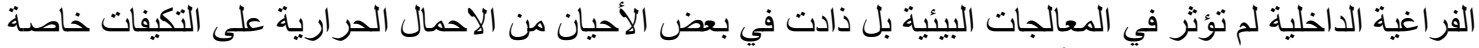

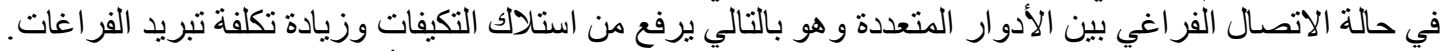

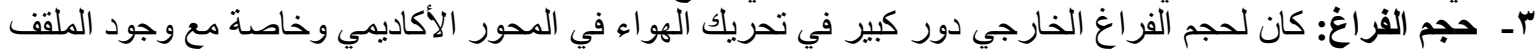

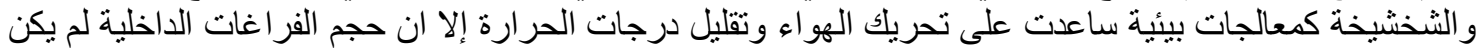

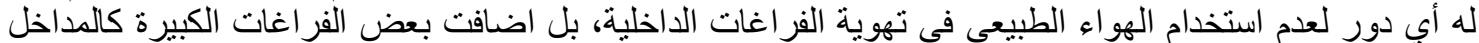

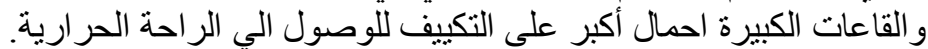

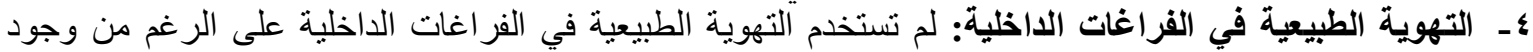

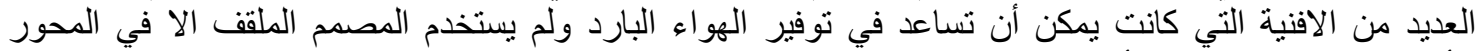
الأكاديمي الرئيسي فقط ولجأ الي التكيف الهو أني في جميع الفر اغات الداخلية. 

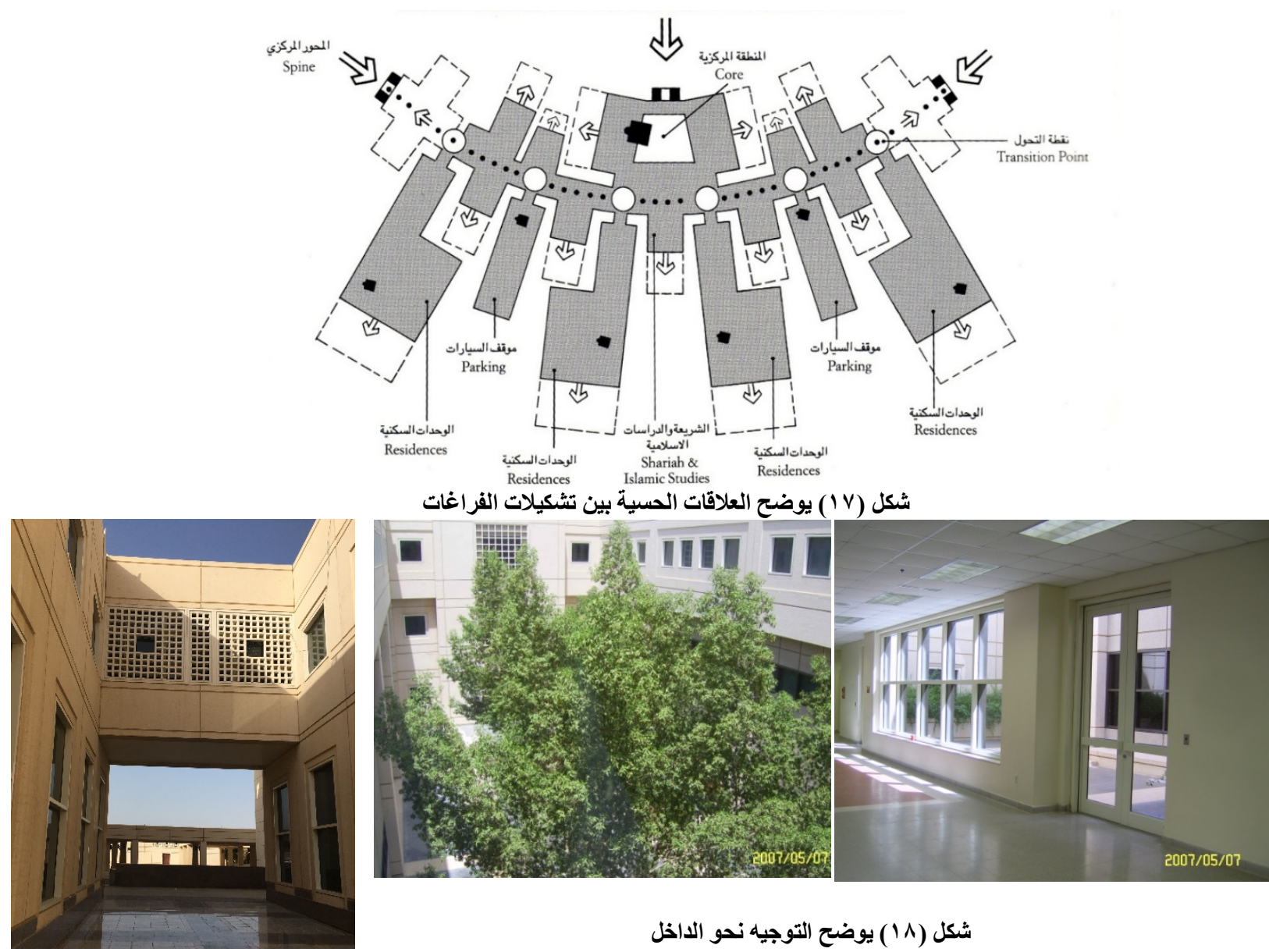

شكل (1) يوضح التوجيه نحو الداخل
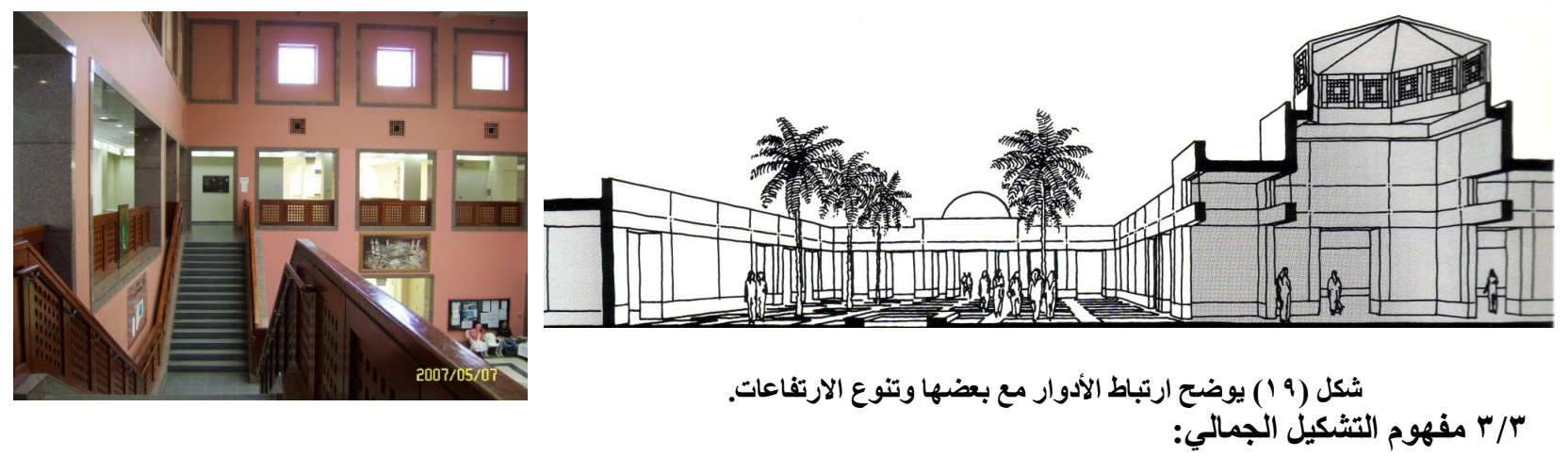

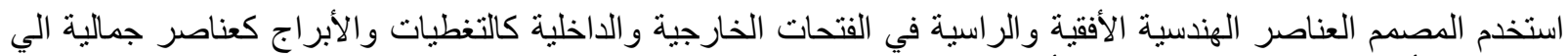

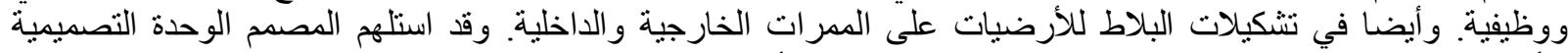

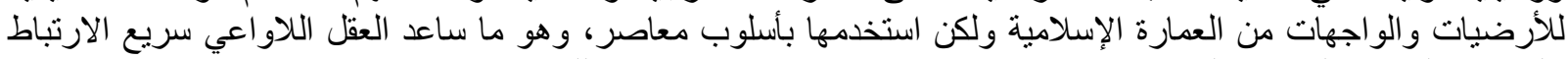

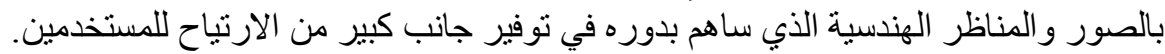

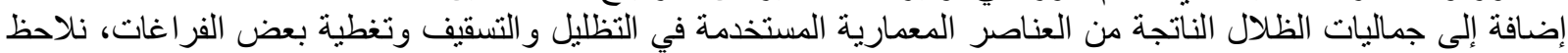

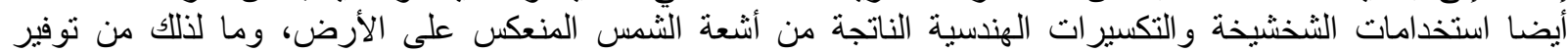
لإحساس هندسية متناغم بشكل كبير مع كليات الهندسة المرتبطة فكريا بذلك. 


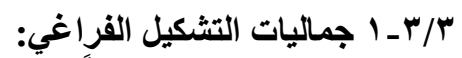

يعتبر الفراغ كما ذكرنا سابقاً هو الوحدة الأهم في التصميم الهعماري، ومقياسه وأبعاده الحركية والجمالية من أهم مقومات

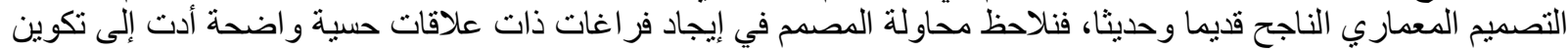

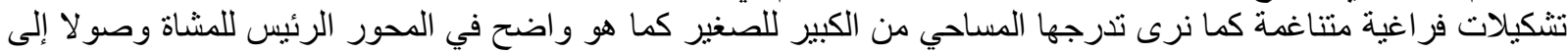

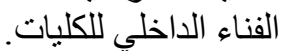

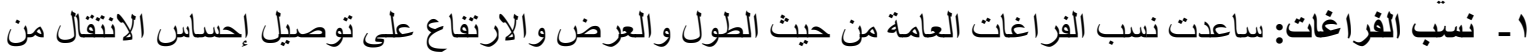

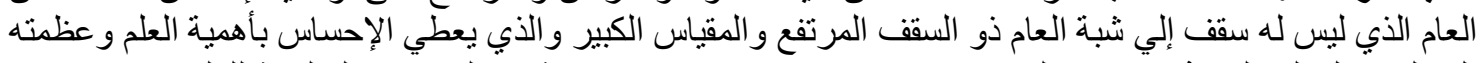

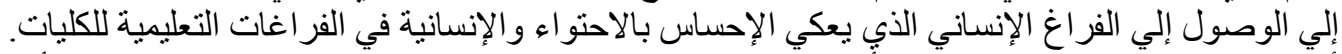

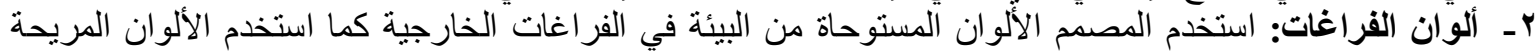

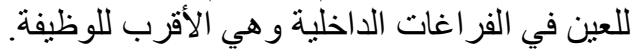

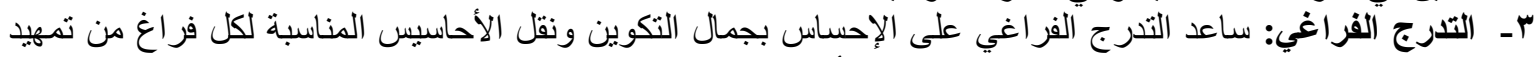

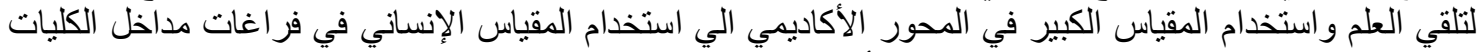

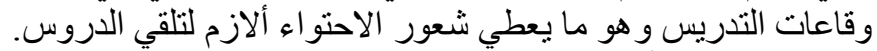

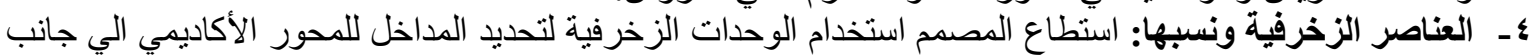

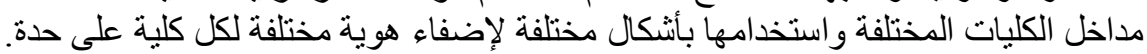

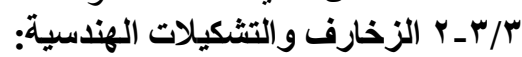

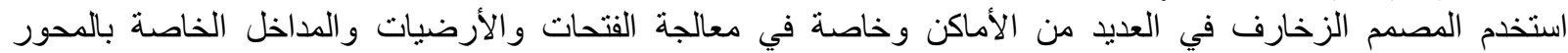
الأكاديمي ومداخل الكليات وقد استلهم الوحدات الزخارف الهن الهندية المستوحاة من العمارة الإسلامية ولكن بمعالجة معاصرة سو اء على مستوى المواد او التشكيل.

1- معالجة الفتحات: استخدم وحدات هندسية مستوحاة من العمارة الإسلامية باستخدام معاصر بنسب مختلفة كوحدة

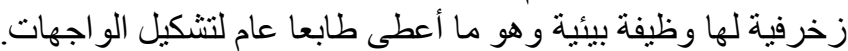

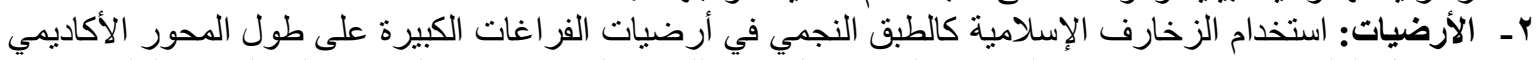

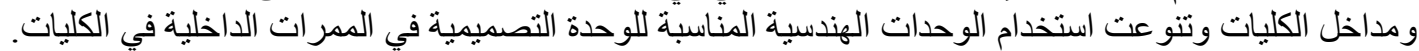

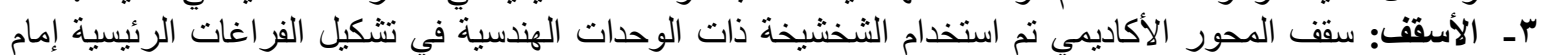

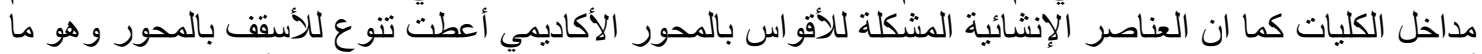

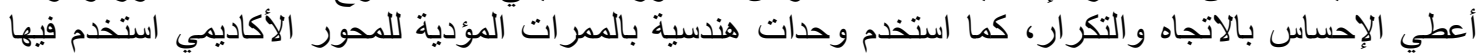

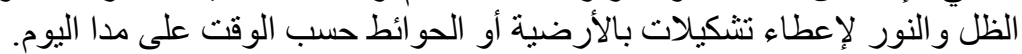

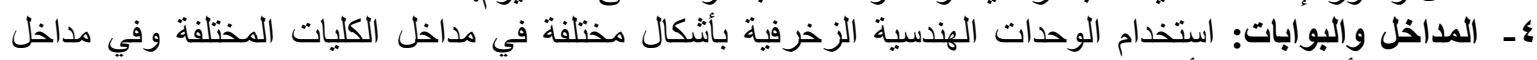

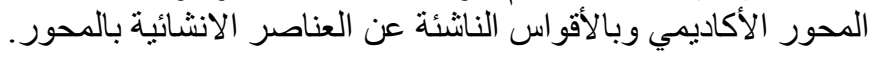
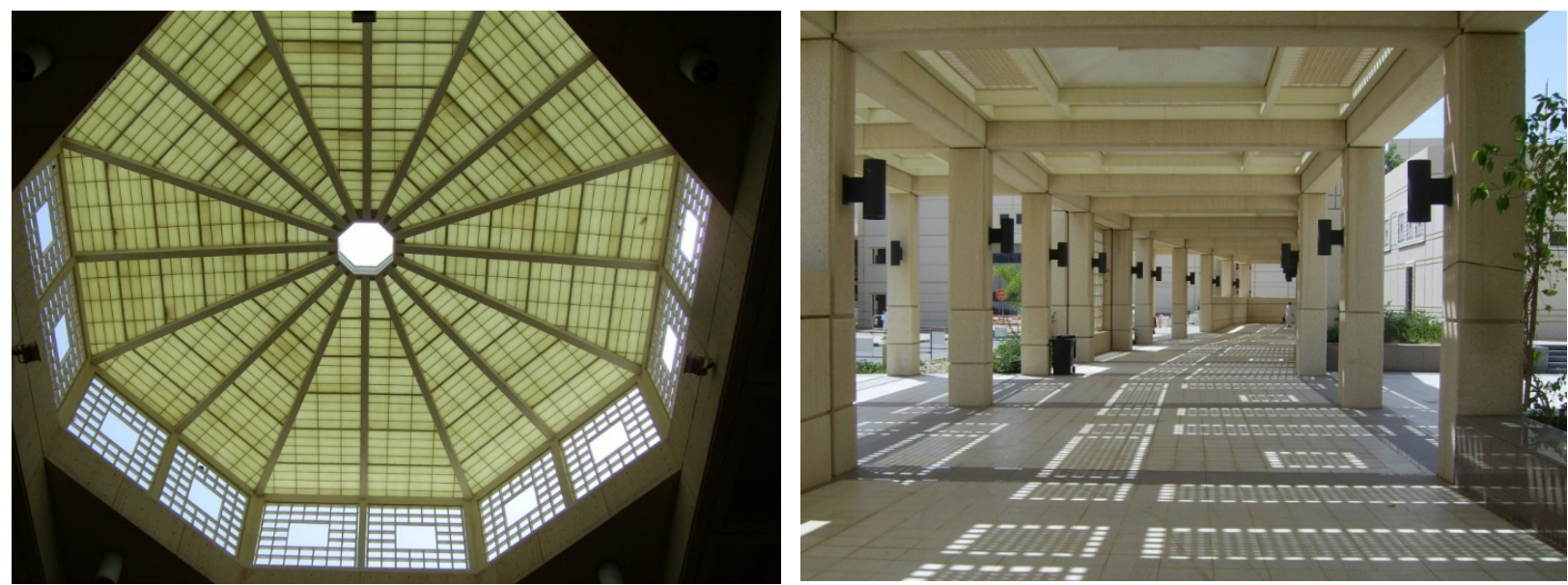

شكل (• (Y) يوضح تنوع التغطيات. 

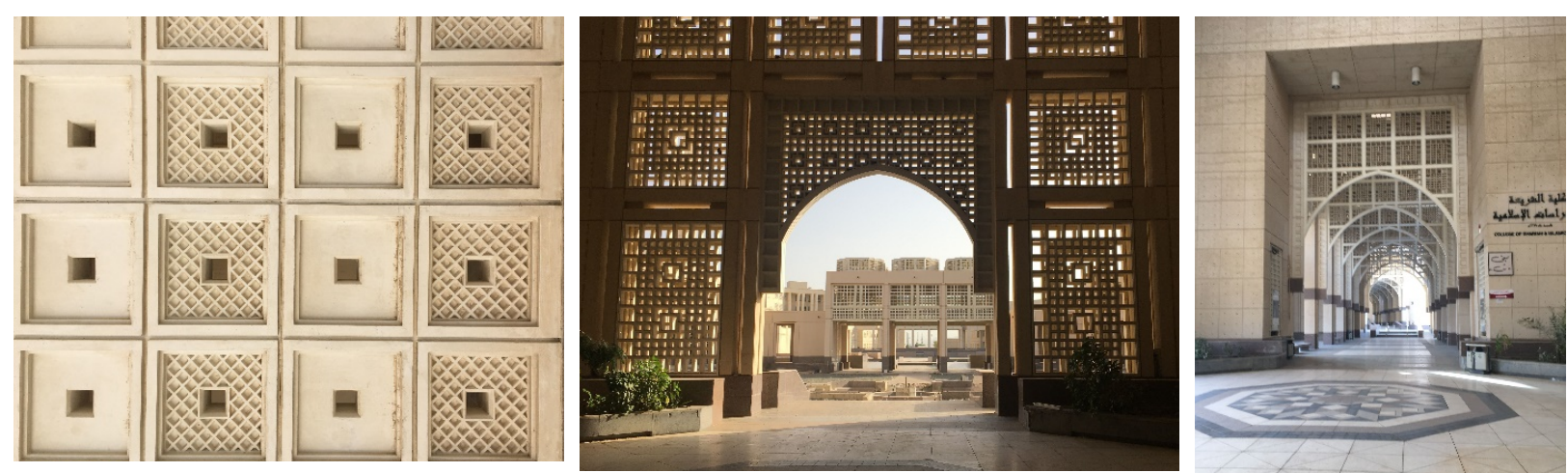

شكل ( ا Y) يوضح استخدام التشكيلات والزخارف الهندسية و ابداع هندسية الظلال- المشربية وانكسار المدخل للخصوصية

ب/ ع تطيق مفاهيم وقيم العمارة الإسلامية على جامعة ام القرى:

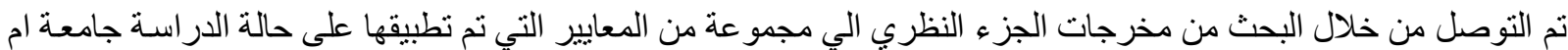

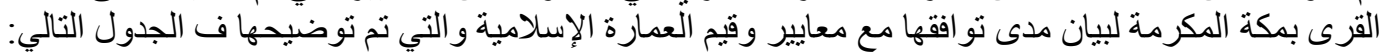

جدول رقم (ץ) تطبيق مفاهيم وقيم العمارة الإسلامية على جامعة أم القرى

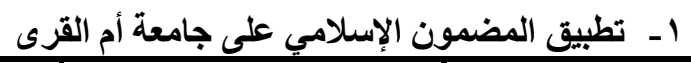

\begin{tabular}{|c|c|c|c|c|c|c|c|c|c|c|c|c|c|c|c|c|}
\hline \multicolumn{2}{|c|}{ الترابط الاجتماعي } & \multicolumn{3}{|c|}{ أهمية المسجد } & \multicolumn{4}{|c|}{ الانسجام مع البيئة } & \multicolumn{4}{|c|}{ البساطة و الوسطية } & \multicolumn{3}{|c|}{ الخصوصية } & \multirow{2}{*}{ | التطبيقات } \\
\hline $\begin{array}{l}\frac{3}{3} \\
\frac{3}{3} \\
\frac{3}{2} \\
\bar{a}\end{array}$ & $\begin{array}{l}\frac{\bar{a}}{9} \\
\frac{9}{y} \\
\bar{y} \\
\frac{9}{3} \\
\frac{9}{3}\end{array}$ & 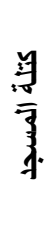 & 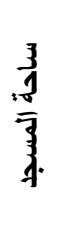 & $\begin{array}{l}\overline{7} \\
\overline{7} \\
\overline{9} \\
\overline{3}\end{array}$ & 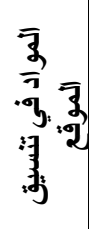 & 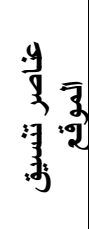 & 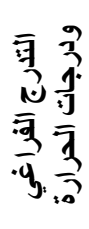 & $\begin{array}{l}\overline{3} \\
\overline{3} \\
\frac{3}{3} \\
3\end{array}$ & $\overline{\overline{3}}$ & 寻. & $\begin{array}{l}\text { 青 } \\
\frac{3}{5} \\
\frac{5}{5}\end{array}$ & 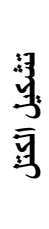 & 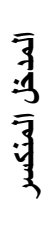 & 章 & 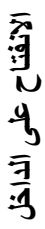 & \\
\hline & & & & & & & & & & & & & & & & المسقط الافقي \\
\hline & & & & & & & & & & & & & & & & تثنكيل الواجهات \\
\hline & & & & & & & & & & & & & & & & تثكيل الكتل \\
\hline & & & & & & & & & & & & & & & & الموقع العام \\
\hline
\end{tabular}

r - ت تطبيق المفهوم البيئي على جامعةُ ام القرى

\begin{tabular}{|c|c|c|c|c|c|c|c|c|c|}
\hline \multicolumn{4}{|c|}{ الفراغ والبيئة } & \multicolumn{2}{|c|}{ مواد البناء } & \multicolumn{3}{|c|}{ التحكم في المناخ } & \multirow[t]{2}{*}{ التطيقات } \\
\hline 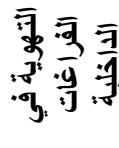 & $\frac{x}{a}$ & 哥高哥 & 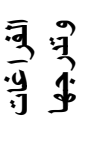 & $\begin{array}{l}\text { 请: } \\
\text { 零 }\end{array}$ & 牙事 & 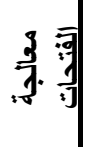 & 氛弱 & 商 & \\
\hline & & & & & & & & & المسقط الافقي \\
\hline & & & & & & & & & تشكيل الواجهات \\
\hline & & & & & & & & & تثكيل الكتل \\
\hline & & & & & & & & & الموقع العام \\
\hline
\end{tabular}


در اسة تحليلية لمفاهيم وقيم العمارة الإسلامية ذات الاستمر ارية الحضارية لجامعة أم القرىـ مكة المكرمة المملكة العربية السعودية

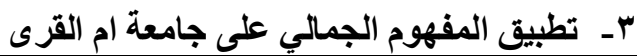

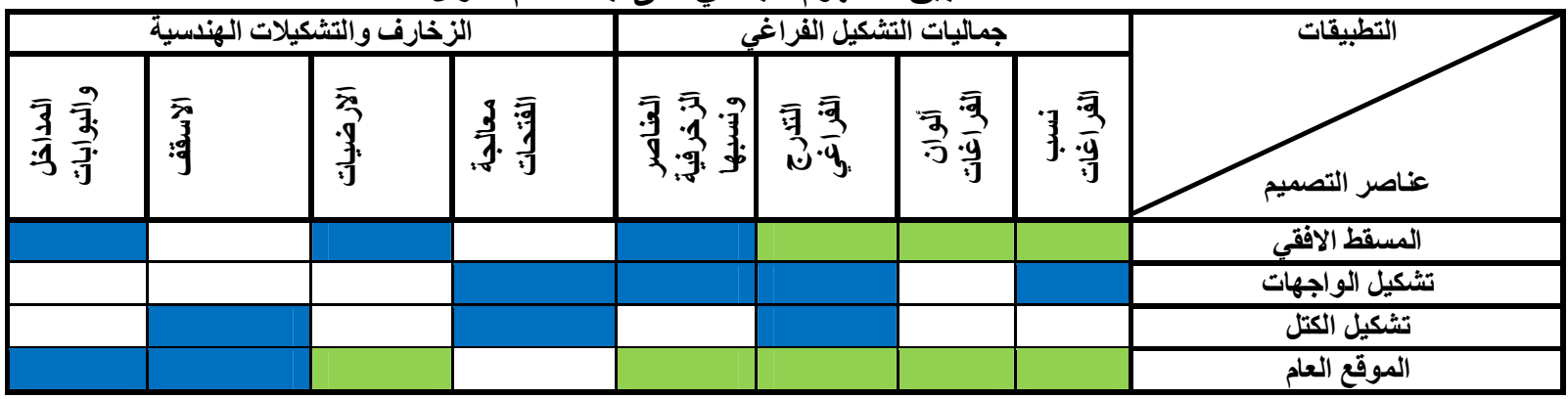

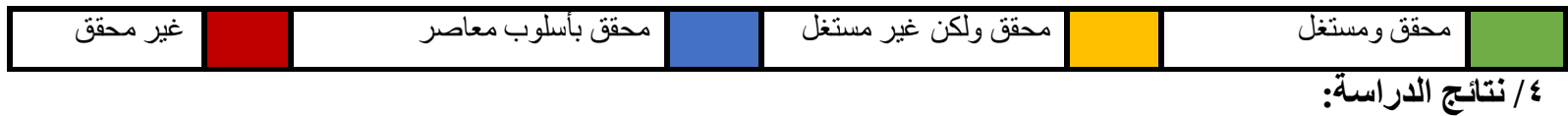

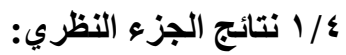

• من دراسة احتياجات الإنسان داخل المبنى، تتضح أهمية توفير الراحة الحر ارية و الضوائية للقيام بالأنشطة المختلفة.

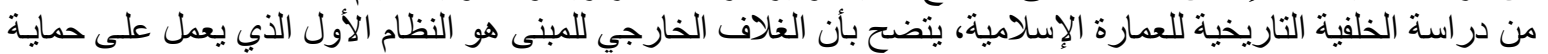

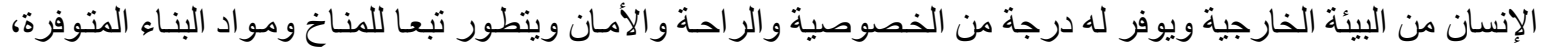

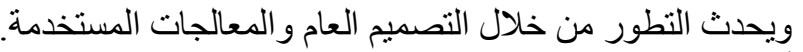

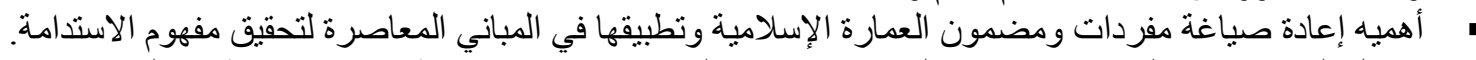

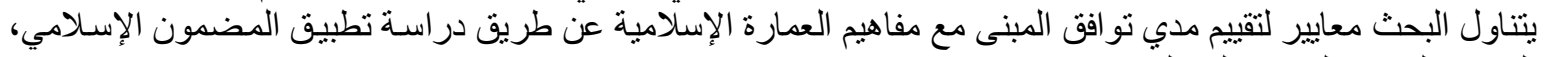

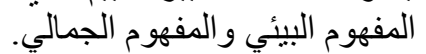

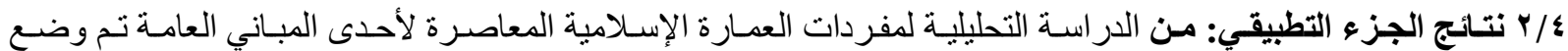

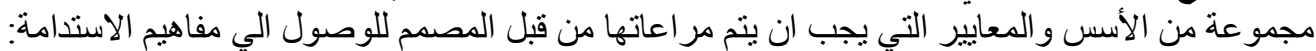

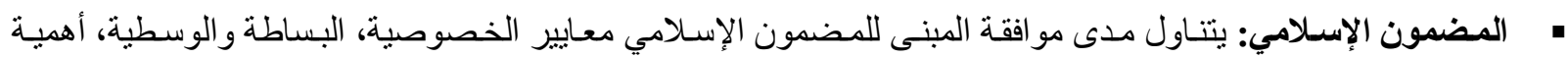

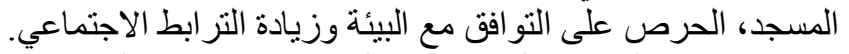

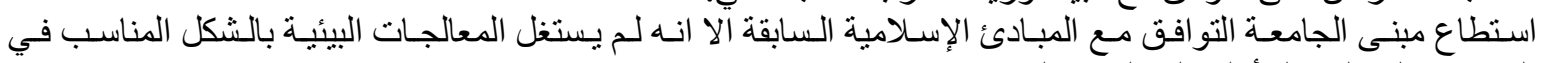

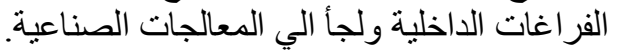

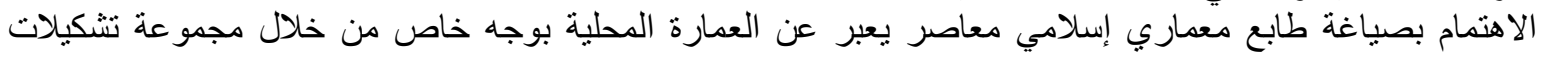

ومعالجات بيئة معاصرة.

استطاع المعماري استخدام الفراغات الخارجية وتدرجها في المعالجات الفيات الحر ارية واستطاع استغلاله في التدرج الحراري

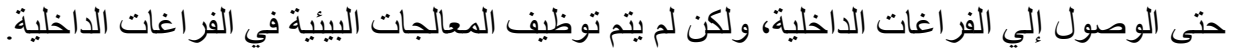

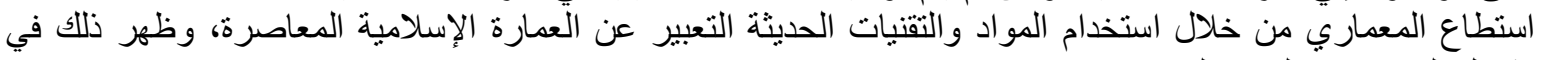

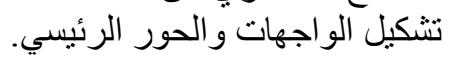

• المفهوم البيئي: يتناول التحكم في المناخ و المواد الطبيعية و الفر اغ و البيئة.

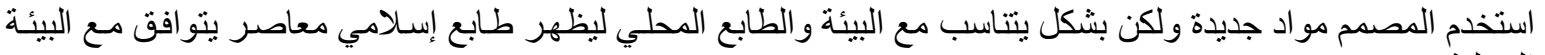

المحلية.

استطاع المصمم التعبير عن المفردات المعمارية البيئية كالفناء والملقف ولكن لم يوظف في معالجة الفراغات الداخلية وتم

الالتجاء إلي التكييف المركزي ولم يستفاد من الأفنية الداخلية.

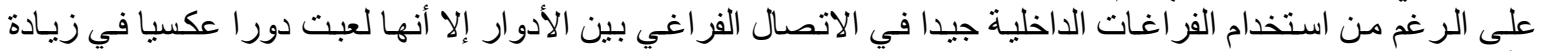

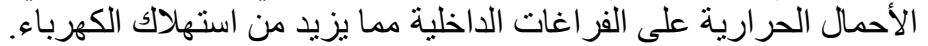

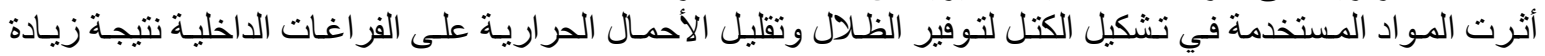

الفتحات المطلوبة للإضاءة الطبيعية.

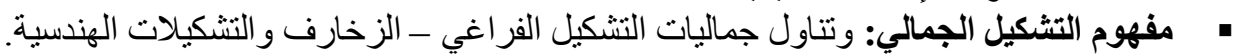

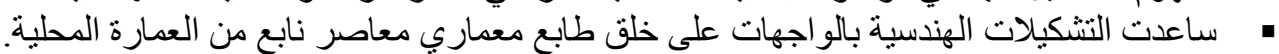


ساعدت التشكيلات الهندسية المتنو عة عند مداخل الكليات لإضفاء شخصية مختلفة لكل كلية بالجامعة مع الاحتفاظ بنفس الوحدة التصميمية التي تعطي طابع و احد عام للمشروع.

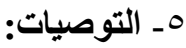

الاستفادة من المفردات التراثية للعمارة الإسلامية في البلاد العربية وتطوير ها والبعد عن النقل المبانشر لهذه الدفردات.

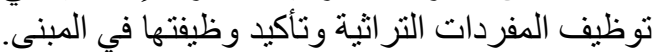

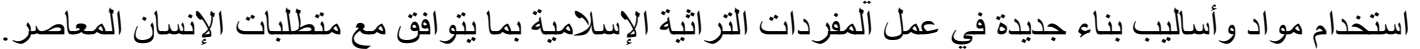

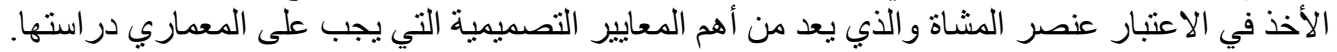

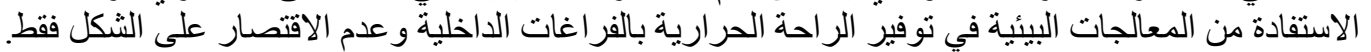

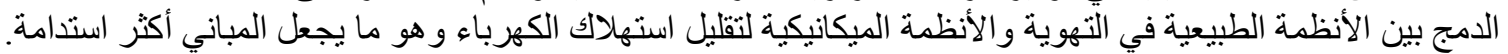

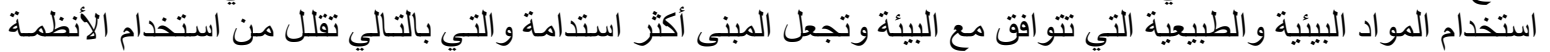

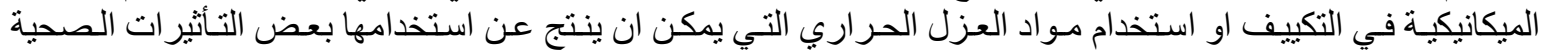

ضرورة مر اعاة مفاهيم وقيم العمارة الإسلامية المعاصرة في تصميم المباني العامة لتحقيق مفاهيم الاستدامة.

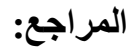

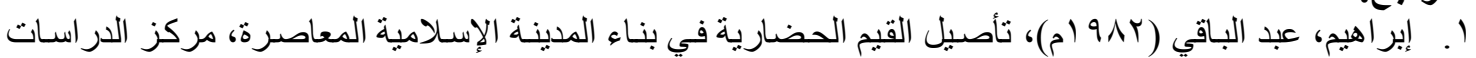

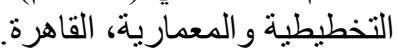

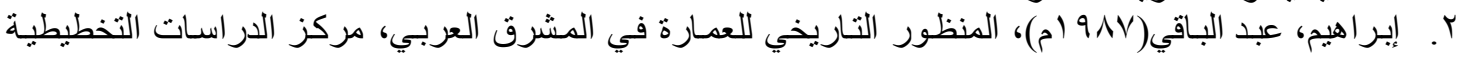
والمعمارية.

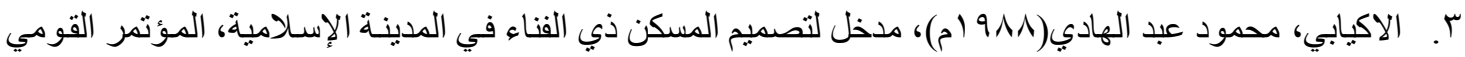
اللار اسات و البحوث البيئية القاهرة.

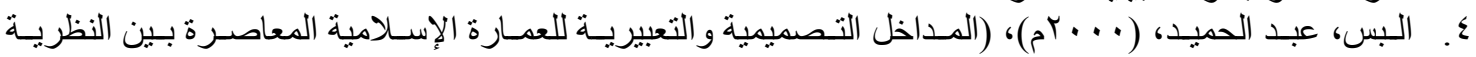

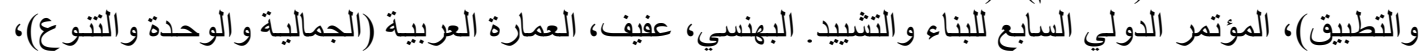

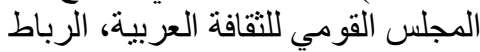

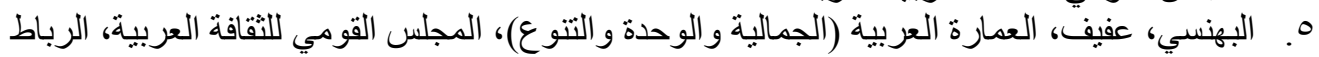

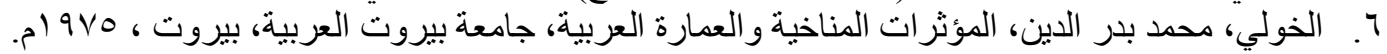

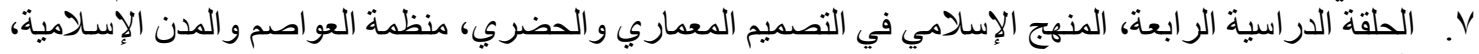

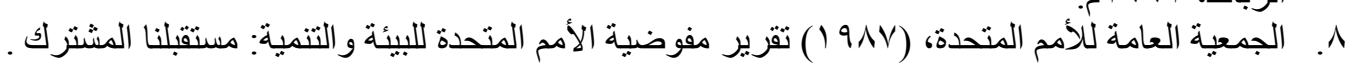

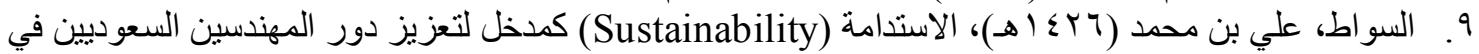

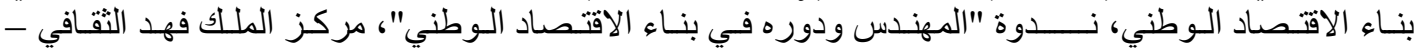

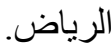

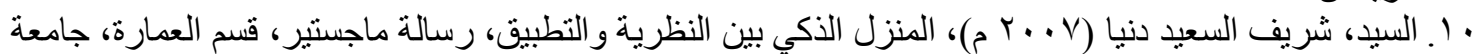

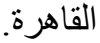

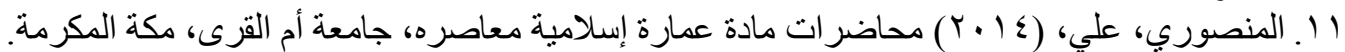

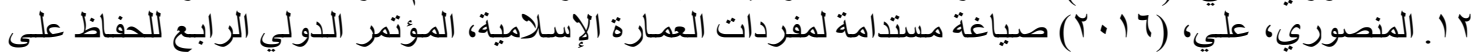
التراث، بلدية دبي.

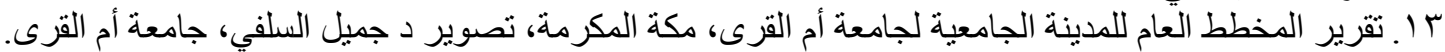

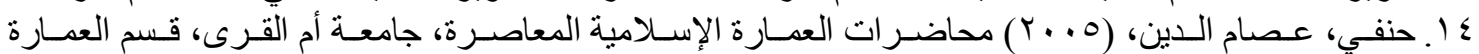
الإسلامية.

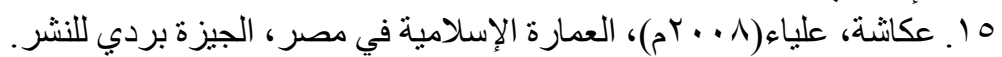

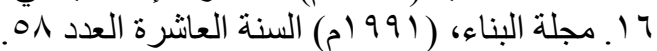

